\title{
UNA NUEVA FACETA PARA "EL SACRIFICADOR". ICONOGRAFÍA TIAWANAKU EN TUBOS DE HUESO DE SAN PEDRO DE ATACAMA, CHILE (400-1000 DC)
}

\author{
A NEW SIDE OF "THE SACRIFICER". TIWANAKU ICONOGRAPHY IN \\ BONE TUBES FROM SAN PEDRO DE ATACAMA, CHILE (400-1000 AD)
}

Helena HortaA, Murrel Pauliny ${ }^{B}$, Boris Santander \& $\&$ Javer Echeverría ${ }^{D}$

Este artículo da a conocer, mediante una aproximación multidisciplinaria un grupo de 14 tubos con iconografía pintada, provenientes de contextos funerarios excavados en distintos cementerios de los oasis de San Pedro de Atacama, cronológicamente asignables al período Medio (ca. 400-1000 DC). Develamos aquí la especial iconografía de estos tubos, cuestión que nos permite entre otros aspectos: ampliar el círculo de las representaciones visuales del arte Tiawanaku, y definir una nueva variante (venado andino o taruca) para el ícono conocido como "El Sacrificador".

Palabras clave: Iconografía tiawanaku, Tubos contenedores de hueso, Parafernalia alucinógena, El Sacrificador, Venado andino, Taruca.

From a multidisciplinary approach this article presents a set of 14 tubes with painted iconography, corresponding chronologically to the Middle Period (circa 400 - 1000 AD), from funerary sites in different cemeteries of the San Pedro de Atacama oases. We show here the special iconography of these tubes which, among other things, allows us to: broaden the range of visual representations of Tiwanaku art and define a new variant (Andean deer or taruca) for the icon known as "The Sacrificer".

Keywords: Tiwanaku iconography, Bone container tubes, Hallucinogen paraphernalia, The Sacrificer, Andean deer, Taruca.

\section{ESTUDIOS PREVIOS SOBRE LOS TUBOS DE HUESO}

Gracias a la incansable labor de rescate patrimonial llevado a cabo durante más de 20 años (1955-1980) por el sacerdote jesuita Gustavo Le Paige en cementerios prehispánicos de los oasis del salar de Atacama, contamos con la evidencia de un conjunto de tubos de hueso con una iconografía especialmente compleja. Las notas de campo de Le Paige (en adelante NLP) dan cuenta del interés particular que despertaron en él estos tubos, lo cual se vio reflejado en el hecho de que les dedicase un acápite completo en la primera y única entrega detallada sobre el tema, acompañada de dibujos en tinta china (“Ix. Huesos pirograbados”; Le Paige 1965: 23-25, Láminas 49-57). Tarragó, por su parte, incluyó este tipo de artefacto en el cruce de información contextual que realizara con los datos de los cementerios excavados por Le Paige (Tarragó 1989: figs. 34 y 35; estas reproducen sin modificaciones los dibujos mencionados).

A Helena Horta, Instituto de Investigaciones Arqueológicas y Museo R. P. Gustavo Le Paige S. J., (IAAM), Universidad Católica del Norte, Chile. orcid: 0000-0003-0831-4322. E-mail: hhorta@ucn.cl

B Muriel Paulinyi, Instituto de Historia, Pontificia Universidad Católica de Valparaíso. orcid: 0000-0003-4890-7755. E-mail: muriel.paulinyi@pucv.cl

C Boris Santander, Universidad Alberto Hurtado, Departamento de Antropología, Santiago de Chile. ORCID: 0000-0002-3292-0675. E-mail: bsantander@uahurtado.cl

D Javier Echeverría, Universidad de Santiago de Chile, Departamento de Ciencias del Ambiente. ORCID: 0000-0002-1688-968X. E-mail: javier.echeverriam@usach.cl 


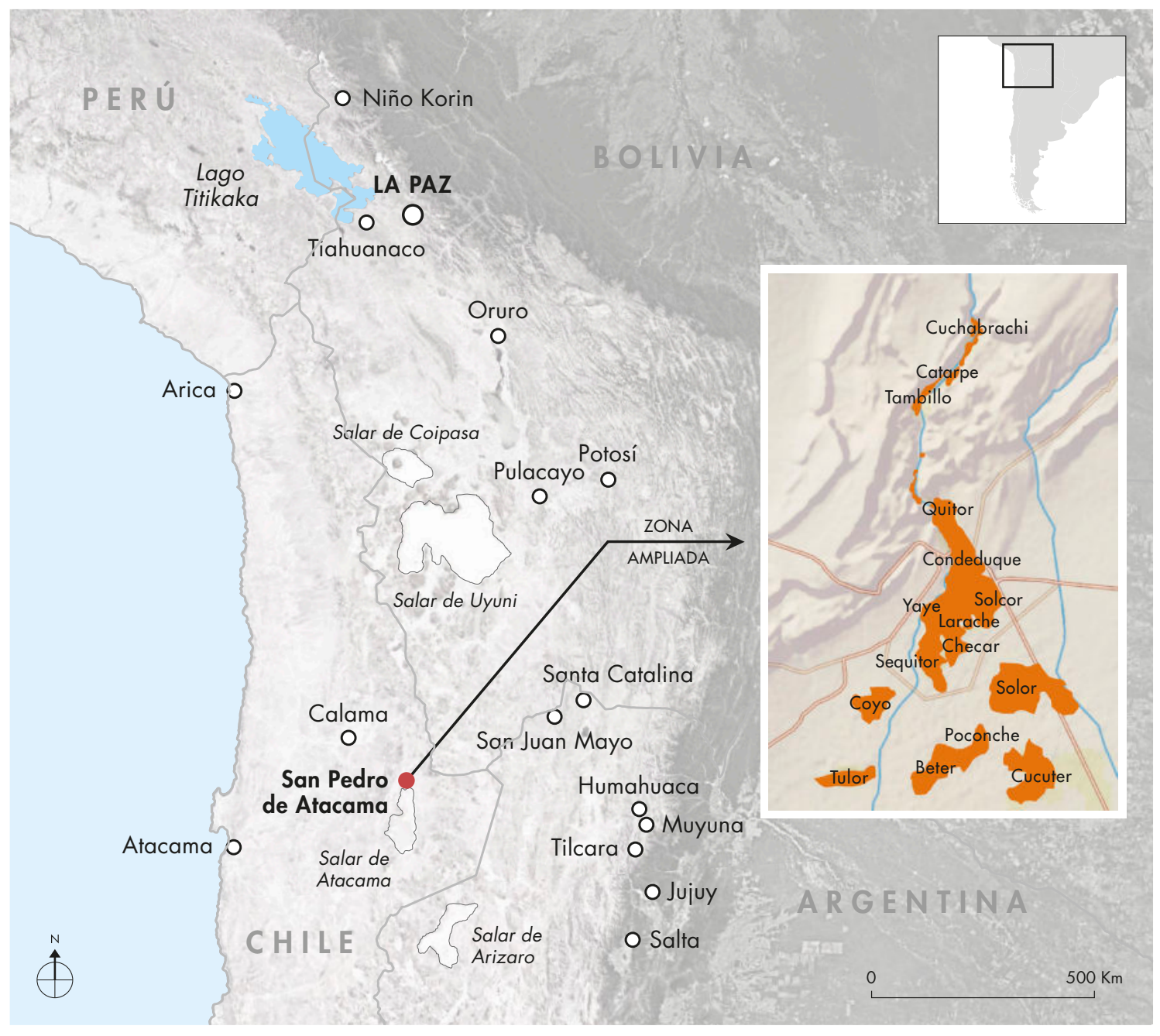

Figura 1. Mapa general de la región con los sitios mencionados en el texto. Figure 1. General map of the region with the sites mentioned in the text.

La mirada atenta de Le Paige le permitió definir a dichos tubos de hueso como "de puro estilo Tiahuanaco" (Le Paige 1964: 61), advirtiendo además semejanzas iconográficas entre algunos tubos y ciertas tabletas de madera para inhalar; al respecto, expresó: "[Los tubos contenedores] están en conexión con tabletas para rapé que representan el mismo tema", aclarando que "nos referimos únicamente a tabletas grabadas [de extensiones planiformes con incisiones lineales, según la nomenclatura introducida por Torres 1985], no a las que tienen el mango esculpido en alto relieve" (Le Paige 1965: 24). Esta afirmación es notable pues, como veremos más adelante, efectivamente la iconografía de algunos de los tubos de hueso, preservados en la colección del
Museo Arqueológico R. P. Gustavo Le Paige S. J. de la Universidad Católica del Norte, presenta estrechas analogías con artefactos de la parafernalia alucinógena (en especial tabletas), descubiertos en tumbas de distintos cementerios del salar de Atacama (fig. 1). Actualmente, existe consenso respecto de que los diversos artefactos de estilo Tiawanaku (entre ellos, cerámica, textiles, etc.) excavados en los oasis sanpedrinos no fueron fabricados localmente, sino que arribaron a Atacama producto de intercambios con poblaciones circun-Titicaca (Oakland 1992; Agüero 2003; Agüero \& Uribe 2014; Stovel 2005, 2008; Llagostera 2006; Niemeyer et al. 2015; Richardin et al. 2015; Horta 2012, 2014; Torres-Rouff et al. 2015; Uribe \& Agüero 2001, entre otros). 


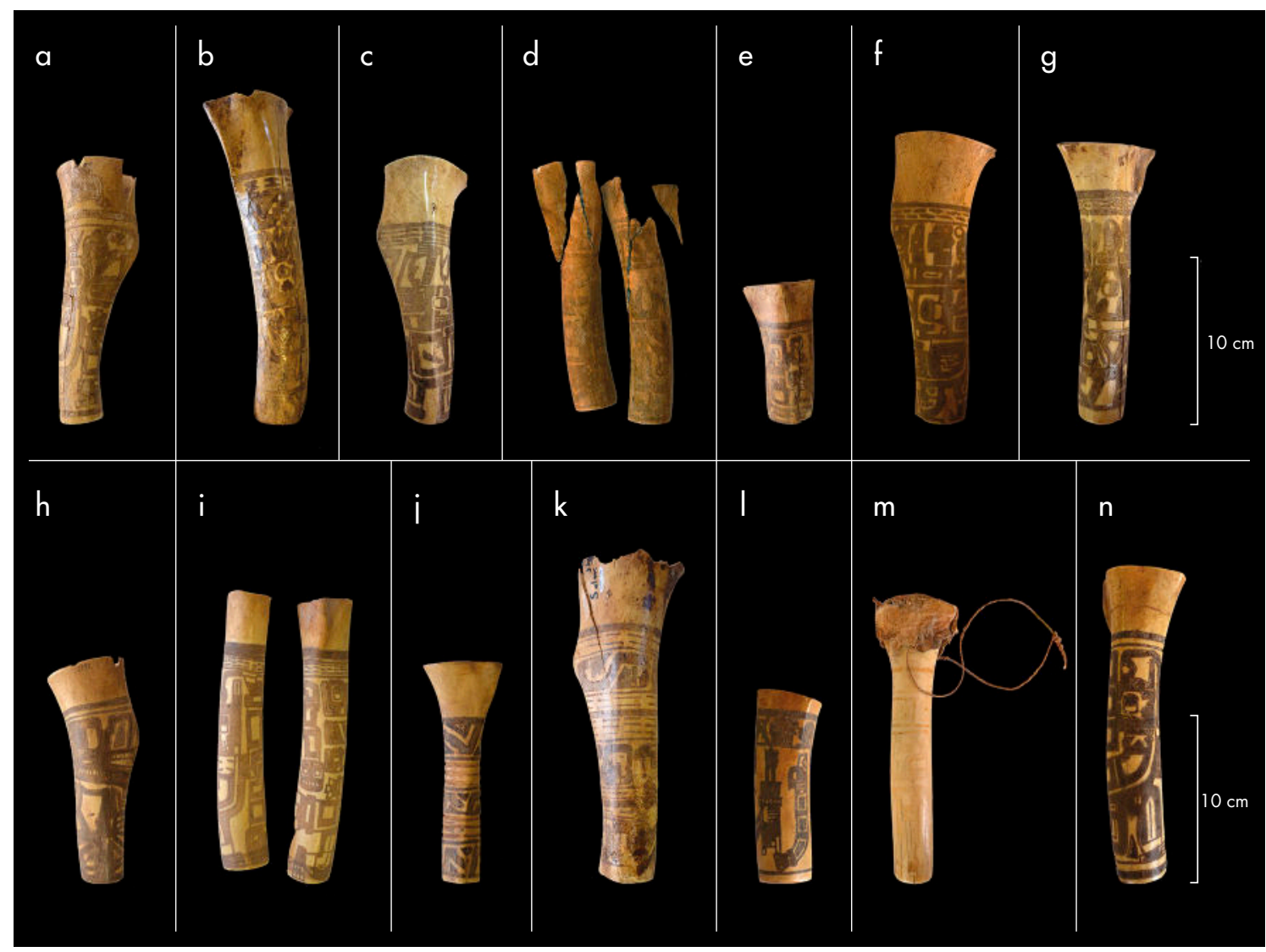

Figura 2. Fotografías de los 14 tubos contenedores analizados. Colección del Museo Arqueológico R. P. Gustavo Le Paige S. J., Universidad Católica del Norte (IIAM-UCN), San Pedro de Atacama, Chile. Véanse datos de proveniencia contextual en tabla 1. Figure 2. Photographs of the 14 container tubes analyzed. R.P. Gustavo Le Paige s. j. Archaeological Museum collection, Universidad Católica del Norte (IIAM-UCN), San Pedro de Atacama, Chile. For contextual provenance data, see table 1.

Le Paige advirtió igualmente la condición especial de la iconografía de este tipo de tubos de hueso, y aunque no llega a definir al personaje representado, señala que "se trata siempre de un mismo y único tema: el sacerdote haciendo la genuflexión, el cetro en la mano, tema repetido 48 veces en la Puerta del Sol de Tiahuanaco" (Le Paige 1965: 24). Este autor no ahondó en el carácter del "sacerdote", tal como podemos hacerlo hoy gracias a la acumulación de investigaciones que abordan la iconografía circun-Titicaca (Posnansky 1945, 1957; Sawyer 1963; Torres 1984a y b, 1985, 1987, 2001; Torres \& Conklin 1995; Reinhard 1991; Cook 1994; Berenguer 1987, 1998, 2000; Agüero et al. 2003; Janusek 2003, 2004a y b, 2006, 2008; Makowski 2001a, 2001b, 2009; Isbell \& Knobloch 2008; Knobloch 2000; Villanueva 2007, entre otros).

\section{MUESTRA RECABADA Y METODOLOGÍA APLICADA}

La búsqueda llevada a cabo en los registros y depósitos del Museo Arqueológico R. P. Gustavo Le Paige S. J. en San Pedro de Atacama, derivó en la detección de 48 tubos de hueso: 28 cilíndricos lisos y sin diseños y 20 de forma troncocónica con diseños, 14 de ellos con iconografía tiwanakota pintada y 6 con iconografía grabada. De estos 14 tubos pintados (figs. 2 y 3 , siglados desde la letra “a” hasta la "n"), 12 presentan iconografía compleja, y dos, diseños simples que incluyen formas naturalistas estilizadas en combinación con motivos geométricos (fig. 2: j y k). En todos los tubos con iconografía pintada se aprecia una franja horizontal que delimita el borde superior del diseño, dependiendo del ejemplar, puede aparecer acompañada de una segunda hilera de puntos, 


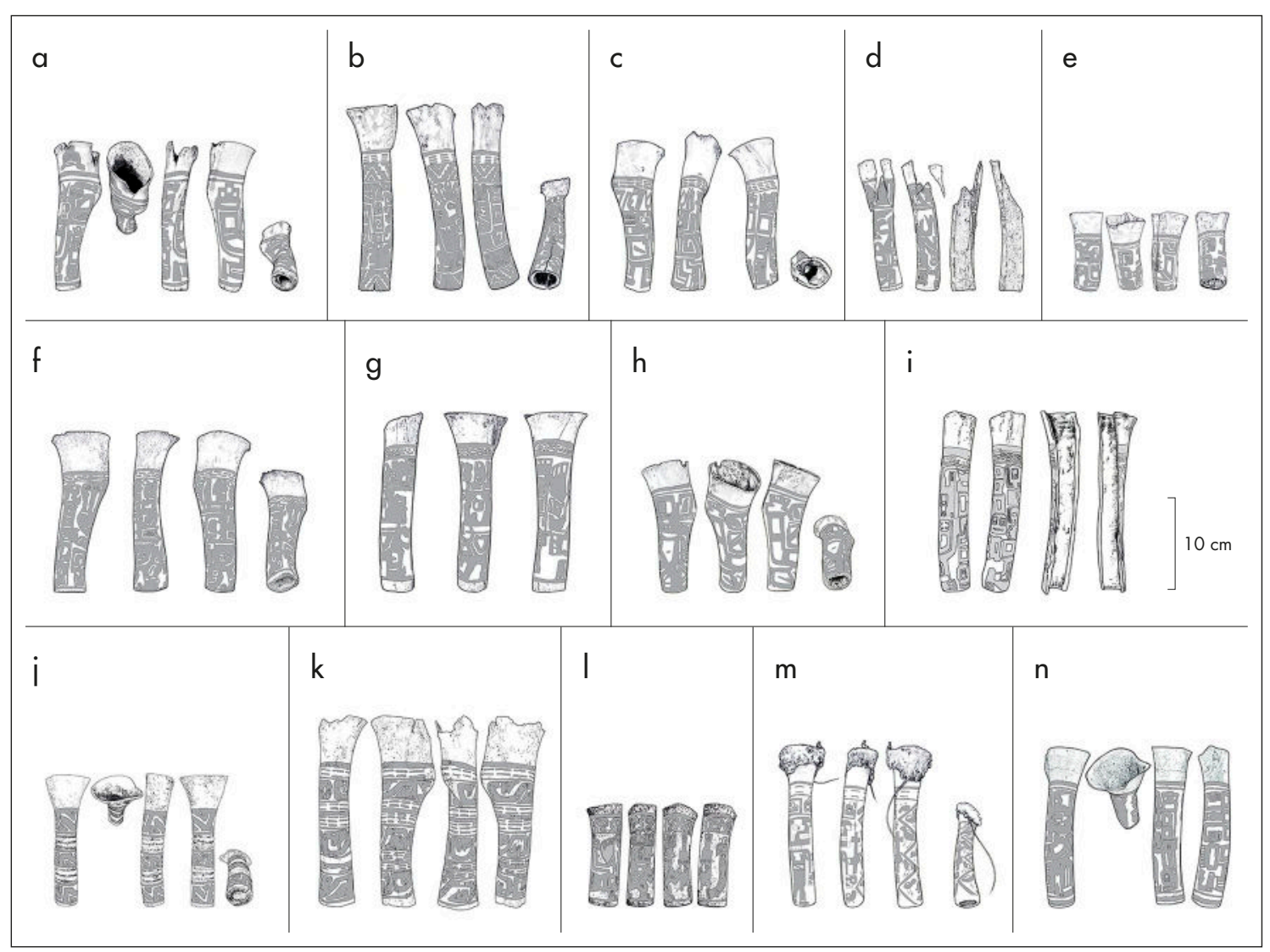

Figura 3. Dibujos de la iconografía relevada de los 14 tubos contenedores analizados. Colección del Museo Arqueológico R. P. Gustavo Le Paige S. J., IIAM-UCN. Véanse datos de proveniencia contextual en tabla 1. (Ilustración: Alex Olave). Figure 3. Drawings of the iconography observed in the 14 container tubes analyzed. R.P. Gustavo Le Paige S. J. Archaeological museum collection, IIAM-UCN. For contextual provenance data, see table 1. (Drawing: Alex Olave).

segmentos ovalados oscuros, o de motivos naturalistas o geométricos (figs. 2 y 3 : j y l).

El análisis iconográfico de los 14 tubos mencionados se basó en la inspección visual directa de cada uno y el registro de sus detalles mediante dibujos a mano alzada y fotografías, todo ello sirvió para que un dibujante profesional reconstruyese el diseño de cada ejemplar bajo la supervisión y cotejo de nuestro equipo. ${ }^{1}$ Paralelamente, los dibujos que realizara Le Paige hace más de 50 años sobre algunos de ellos fueron revisados en detalle y complementados - cada vez que fue necesariocon aquellos detalles iconográficos que escaparon a su examen (situación que se dio en varios casos, como se explicará más adelante). La puesta en práctica de este método permitió elaborar reproducciones más precisas, ampliar con cinco el número de tubos dibujados y definir los nuevos elementos iconográficos detectados en ellos.
En base a esto, se ha logrado establecer que El Sacrificador ("decapitador", "chachapuma", "hombre-felino", "hombre-felino decapitador", "naqak" o "degollador", entre otras denominaciones), es el tema más recurrente, apareciendo de manera explícita en seis de los 12 tubos que presentan iconografía compleja. Los seis ejemplares restantes representan a dos pájaros antropomorfizados en posición genuflexa con cetros en las manos (figs. 2i y $2 n$ ), a tres felinos antropomorfizado en la misma posición (fig. 4a, b, c), y a un humano alado erguido en dos piernas, semejante a los del friso de la Puerta del Sol en Tiahuanaco (fig. 4d).

En términos generales, en los estudios de iconografía altoandina (Pucara, Huari, Tiawanaku) existe el criterio que considera como tal a El Sacrificador cuando se observa la representación explícita de los atributos de la decapitación, ya sea porque el personaje 
a

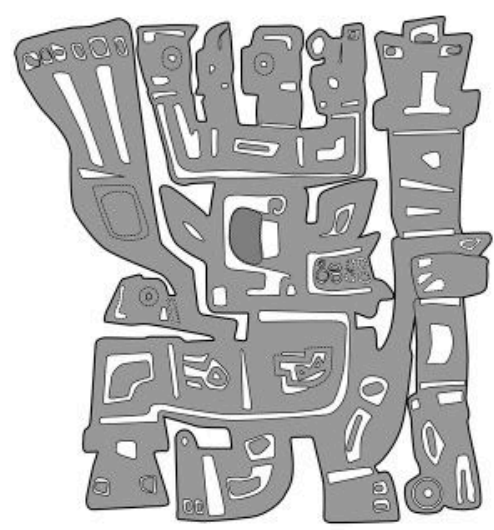

C

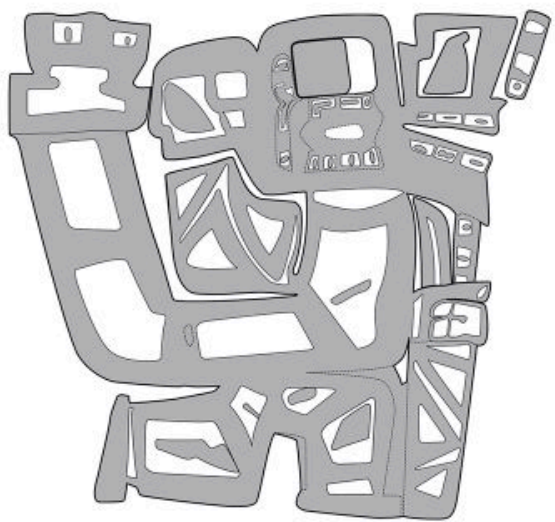

b

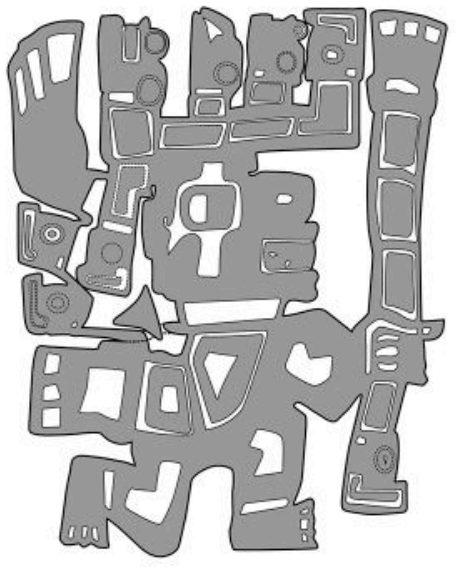

d
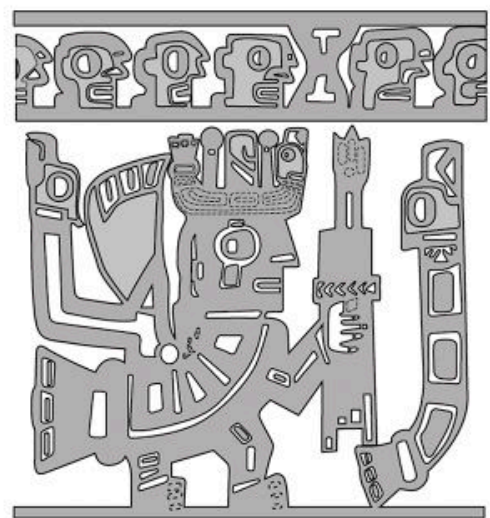

Figura 4: a) tubo contenedor "B" con felino alado de la tumba 1973-77 del cementerio Quitor 5; b) Tubo contenedor "B" con felino alado de la tumba 2153 [2752] del cementerio Quitor 5; c) Tubo contenedor con felino alado de la tumba 38 del cementerio Solcor 3; d) Tubo contenedor con personaje humano alado de Solor 3, posible tumba 38. Colección del Museo Arqueológico R. P. Gustavo Le Paige S. J., IIAM-UCN . (Ilustración: Alex Olave). Figure 4: $a$ ) container tube " $B$ " with winged feline from grave 1973-77 at Quitor 5 cemetery; $\boldsymbol{b}$ ) Container tube "B" with winged feline from grave 2153 [2752] at Quitor 5 cemetery; $c$ ) Container tube with winged feline from grave 38 at Solcor 3 cemetery; d) Container tube with winged human character from Solor 3, possibly grave 38. R.P. Gustavo Le Paige s. j. Archaeological Museum collection, IIAM-UCN. (Drawing: Alex Olave).

sostiene en las manos la cabeza cortada y el instrumento cortante, ya sea porque su tocado incorpora miembros cercenados del cuerpo humano (Valcárcel 1959; Núñez 1964; Paredes 1984; Torres 1984a y b, 1985; Cook 1994; Llagostera 1995, 2006; Berenguer 2000; Chávez 2002; Sagárnaga \& Korpisaari 2007, entre otros). La definición de la variante felino para El Sacrificador se establece -además de las fauces con colmillos entrecruzados- en base a las tres posibles representaciones de su nariz: como círculo concéntrico (véase la túnica en tapicería de Moquegua; Minkes 2005: fig. 2.5), como apéndice prominente (véase dintel de la calle Linares o la túnica de Pulacayo; Cook 1994: lám. 54a; Agüero 2007: fig. 8), o como forma escalerada (tal como se puede observar en un quero de Putuni; Couture \& Sampeck 2003: fig. 9.28). La variante humana es mucho menos 

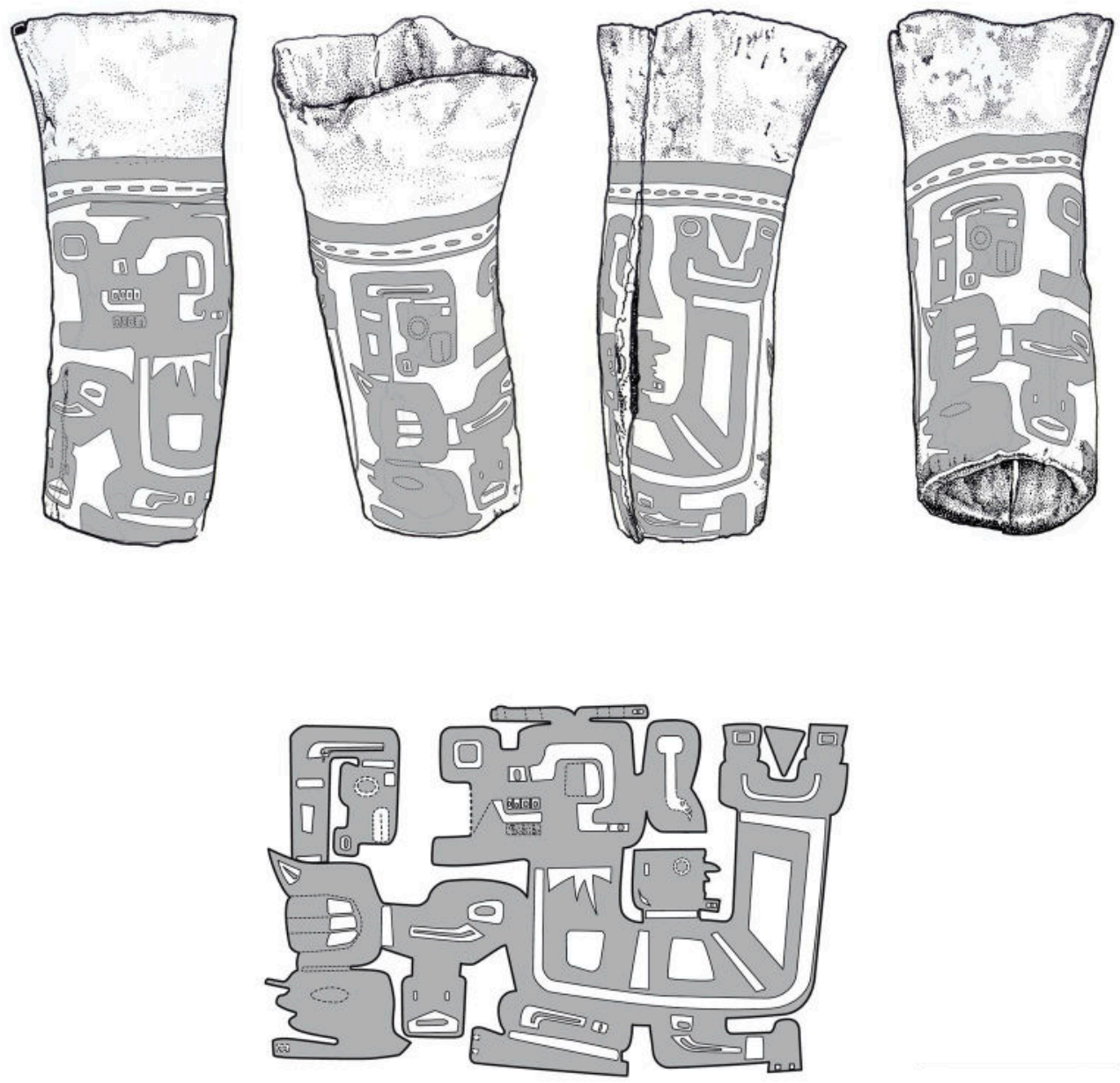

0 $3 \mathrm{~cm}$

Figura 5. Tubo contenedor con Sacrificador-felino de la tumba 1371-72 del cementerio Quitor 4. Colección del Museo Arqueológico R. P. Gustavo Le Paige S. J., IIAM-UCN. (Ilustración: Alex Olave). Figure 5. Container tube with feline Sacrificer from grave 1371-72 at Quitor 4 cemetery. R.P. Gustavo Le Paige s. j. Archaeological Museum collection, IIAM-UCN. (Drawing: Alex Olave).

frecuente, y corresponde a una figura antropomorfa erguida en dos piernas que -aunque es representada en una posición corporal totalmente humana- en ocasiones exhibe colmillos entrecruzados y orejas de felino, acompañados de nariz triangular o escalerada (véase Posnansky 1945: plancha XXb, así como chachapumas tallados en bloques pétreos, Manzanilla \& Woodard 1990: fig. 14).
Con la revisión de los tubos contenedores de la muestra, pudimos constatar que el tema de El Sacrificador aparecía en sus versiones felina y humana solo en dos ejemplares (figs. 5 y 6 , respectivamente); ${ }^{2}$ al mismo tiempo, en los cuatro ejemplares restantes se detectó una variante o connotación hasta aquí no identificada para dicho personaje, a la cual hemos denominado Sacrificadortaruca, y sobre cuya iconografía entregaremos aquí un 

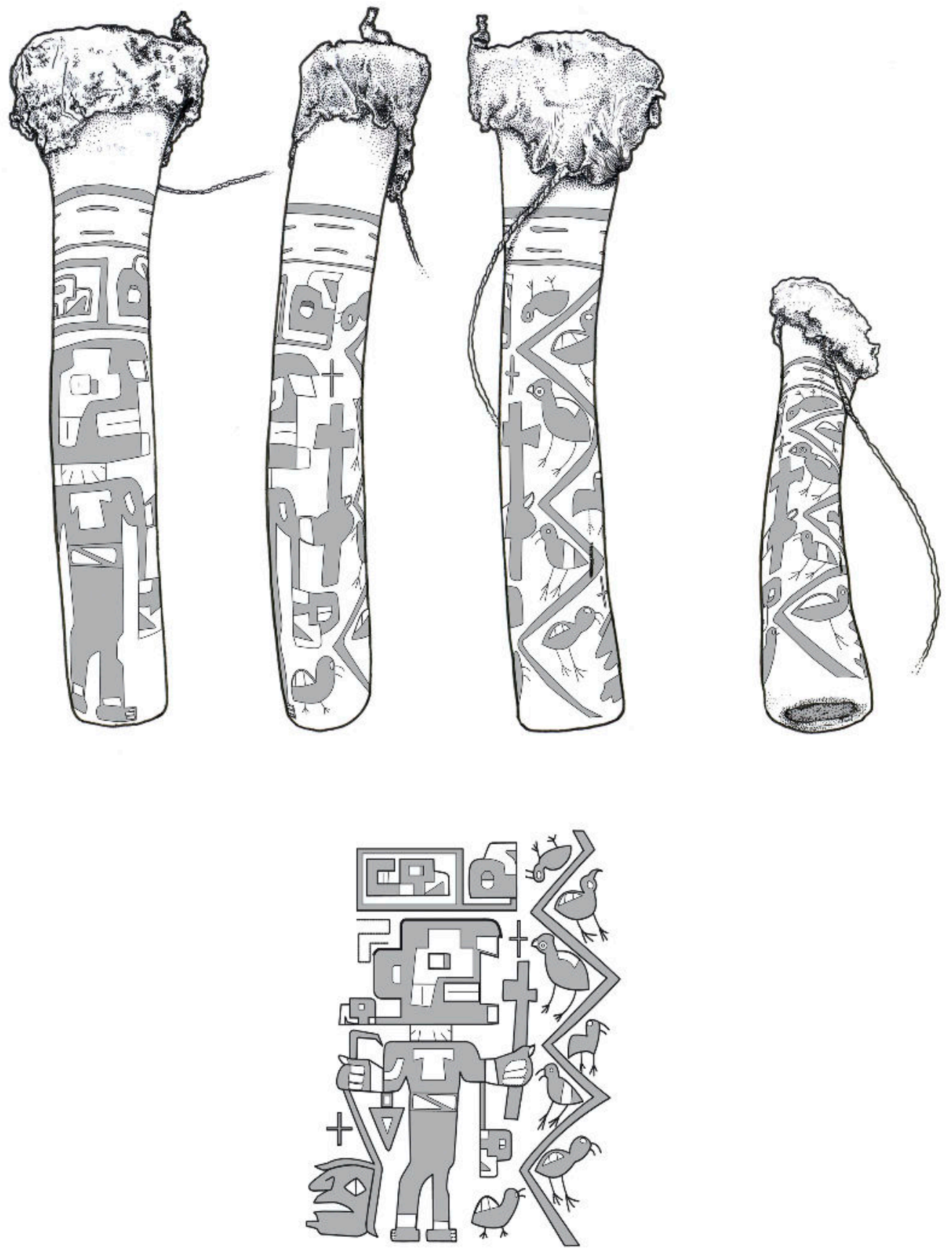

0

$3 \mathrm{~cm}$

Figura 6. Tubo contenedor con Sacrificador-humano sin proveniencia precisa de cementerio. Colección del Museo Arqueológico R. P. Gustavo Le Paige S. J., IIAM-UCN. (Ilustración: Alex Olave). Figure 6. Container tube with human Sacrificer and no precise cemetery provenance. R.P. Gustavo Le Paige S. J. Archaeological Museum collection, IIAM-UCN. (Drawing: Alex Olave). 
detallado análisis. La denominación obedece al hecho de que en tales representaciones, además de portar al igual que los sacrificadores felino y humano los atributos propios de la decapitación, exhibe adicionalmente en el tocado cuernos o astas del venado andino o taruca (Hippocamelus antisensis D’Orbigny, 1834). Sobre este animal hay que mencionar la existencia esporádica de astas provenientes de excavaciones arqueológicas. En el Museo de Tiahuanaco se exhiben astas de venado en estado natural, así como instrumentos formatizados del mismo material. Además, entre el material arqueológico proveniente del noroeste de Argentina de la colección del National Museum of the American Indian, en Washington, figura una cornamenta fracturada en uno de sus extremos ( $\left.\mathrm{N}^{\circ} 133592.000\right)$. Asimismo, son varios los trabajos arqueológicos que consignan la temprana presencia de punzones de astas de este animal en el noroeste de Argentina (Aschero 1979, Lema 2017). En Bolivia, en las cuatro esquinas del palacio o residencia de elite de la plataforma de Putuni fueron encontrados entierros humanos fundacionales; en la esquina sudeste se descubrió a un adulto y un niño con un ajuar que incluía dos cuernos de venado (Kolata 1993: 159).

Paralelamente, y en relación con sitios del altiplano boliviano, logramos identificar otros tres tubos con representación de El Sacrificador-taruca, los cuales fueron incluidos en el análisis iconográfico que presentaremos más adelante.

La aparición de El Sacrificador con atributos de venado andino en estos tubos alcanza especial relieve. En primera instancia, porque la figura de dicho animal es muy poco frecuente en otros soportes del arte tiwanakota y su representación de cuerpo entero hasta el momento no ha sido registrada. Esta situación contrasta con la profusión de imágenes que exhibe el felino en el mismo sistema visual. Actualmente, se cuenta con la imagen en una cerámica de Kherikala de un personaje con cuernos de taruca y pierna cortada en el tocado, el cual fuese considerado por Cook (aunque sin advertir su condición de taruca; Cook 1994: lám. 50a y b) como similar al tocado del tubo 2153 del cementerio Quitor 5 que en este trabajo veremos en detalle.

Por otra parte, entre las ofrendas cerámicas de Conchopata, Perú, la autora citada publica imágenes de la Deidad Frontal (Front face deity) y de Acompañantes de Perfil (Profile attendants) que -ya sea en el tocado de los primeros, o surgiendo de la boca o pie de los segundos- exhiben astas o cabezas de un animal, que nosotros reconocemos como de ciervo andino (Cook 1984: chart 3, pág. 69). Igualmente para Perú, en la imagen tejida en una túnica se puede observar la imagen de El Sacrificador con astas en el tocado (Möntell 1929: fig. 68). Para Bolivia damos cuenta de otros casos cerámicos más: el de una vasija modelada proveniente de Cochabamba, cuya mitad inferior es una cabeza de venado (Ibarra Grasso y Querejazu 1986: 244), así como el de dos queros, uno proveniente de Pariti que representa una cabeza de taruca con una "corona", que en nuestra interpretación podría corresponder a un asta estilizada (Villanueva \& Korpisaari 2013: fig. 4, "queros inusuales"), y el otro publicado por Posnansky proveniente de Tiahuanaco, igualmente exhibe una "corona" de cuatro puntas o ramas semejante a la representación de las astas del venado en los tubos contenedores (Posnansky 1945: lám. xva). A esto hay que agregar dos fragmentos de escudilla recuperados en Putuni de contextos funerarios de época Tiawanaku Iv, en los cuales se aprecian cabezas con astas y orejas erguidas (Couture \& Sampeck 2003: fig. 9.22a y 9.26). Los casos mencionados corresponden solo a representaciones en cerámica, resultando llamativa su ausencia en la litoescultura altiplánica.

En este punto, es necesario destacar que en el análisis iconográfico realizado por Trigo en torno a los atributos de un personaje humano que ha denominado "arquero", incluye un atributo que se localiza consistentemente en la espalda de dicho personaje, y por lo cual ha sido considerado por dicho autor como "cola". Sin embargo, creemos que de acuerdo con algunas de las formas que presenta -objeto dividido en dos ramas a partir de una base común-, bien podrían tratarse de cornamentas de taruca (Trigo 2013: tabla 3).

Por otra parte, nuestra investigación también apuntó a esclarecer la especie animal de la cual fueron fabricados estos tubos, ya que en el pasado se sostuvo que correspondían a huesos de felino, sin haberse verificado tal propuesta (Tarragó 1989). Con este propósito se sometió a examen a los ya mencionados 48 tubos de hueso de la colección del Museo Arqueológico R. P. Gustavo Le Paige S. J., para lo cual se consideraron los tubos cilíndricos lisos sin diseños $(\mathrm{N}=28)$ y los troncocónicos con diseños pintados o grabados ( $\mathrm{N}=20$ ) (Santander Ms. 2016). Paralelamente, residuos extraídos del interior de varios de estos tubos se sometieron a análisis químico (tabla 1), con el fin de determinar su contenido. 


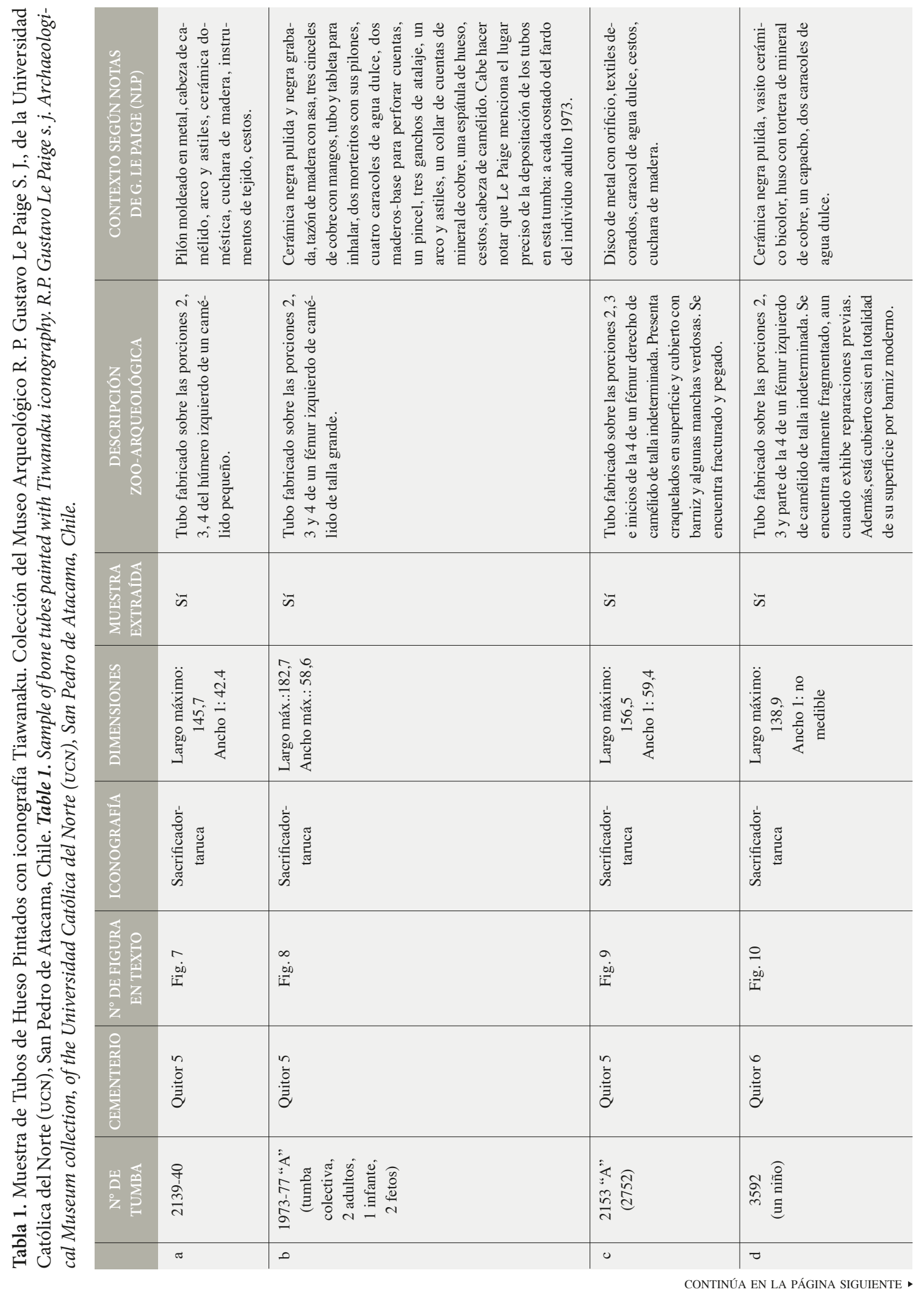




\begin{tabular}{|c|c|c|c|c|c|}
\hline 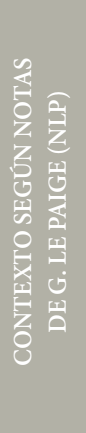 & 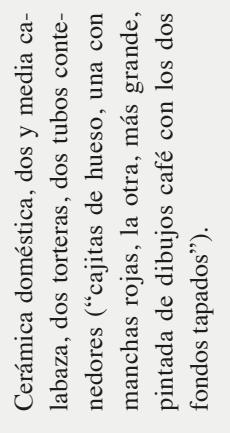 & 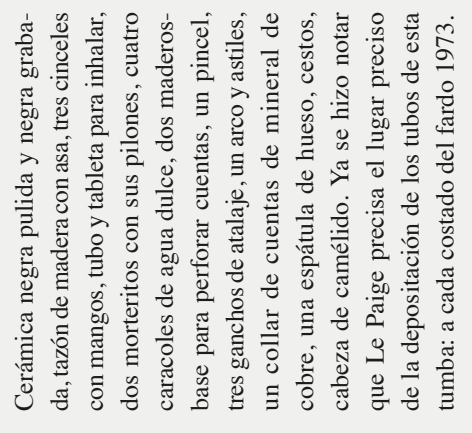 & 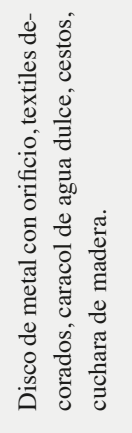 & 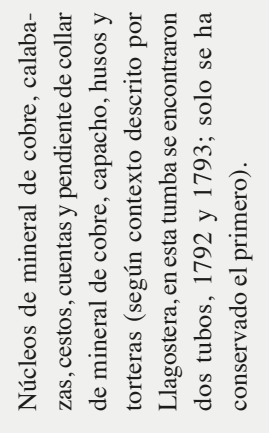 & 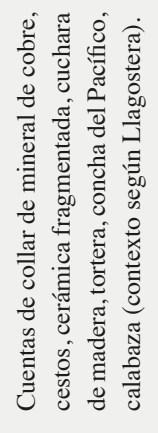 \\
\hline $\begin{array}{l} \\
0 \\
z \\
0 \\
0 \\
0 \\
0 \\
0 \\
0 \\
0 \\
0 \\
0 \\
0 \\
0 \\
0 \\
0 \\
0 \\
0 \\
0\end{array}$ & 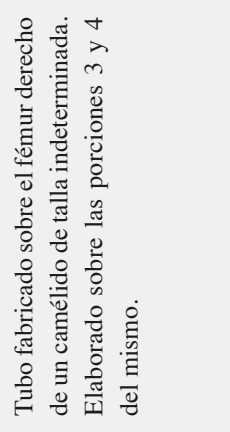 & 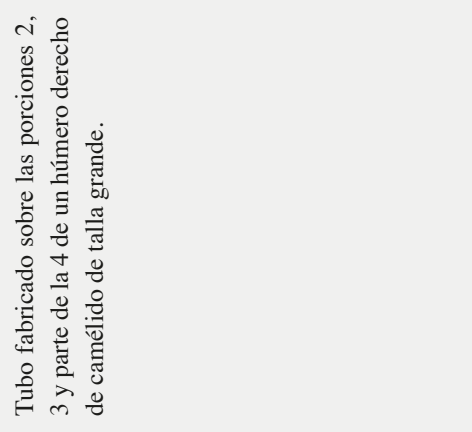 & 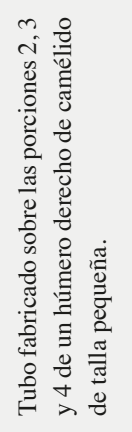 & 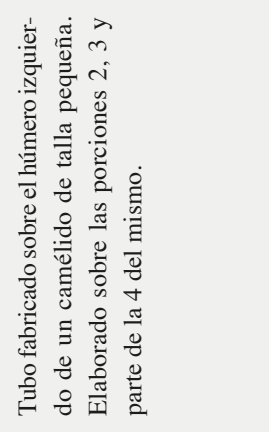 & 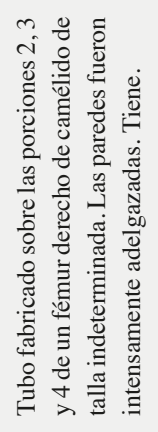 \\
\hline 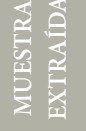 & $\stackrel{\circ}{z}$ & is & is & $\stackrel{\circ}{z}$ & is \\
\hline 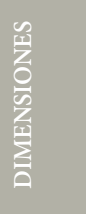 & 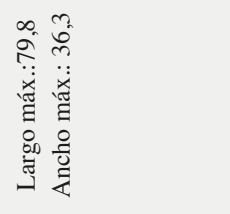 & 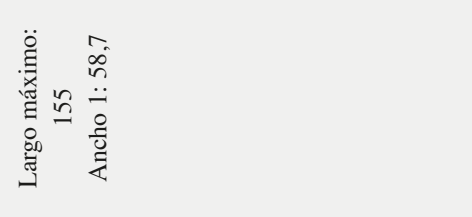 & 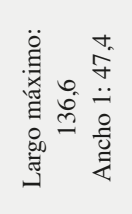 & 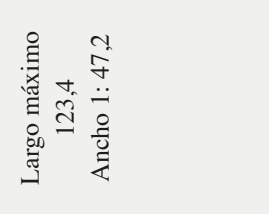 & 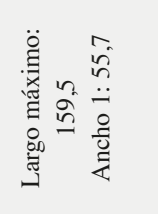 \\
\hline $\begin{array}{l}\frac{1}{12} \\
\frac{3}{3} \\
0 \\
0 \\
0 \\
0\end{array}$ & 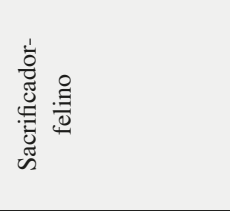 & 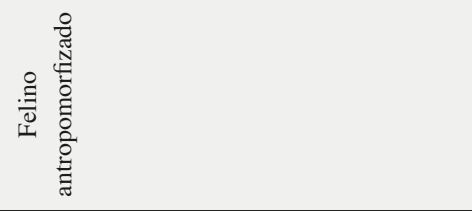 & 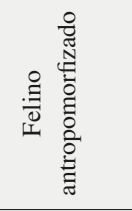 & 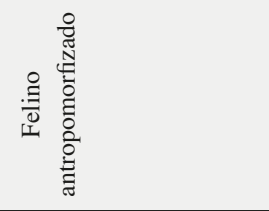 & 高 \\
\hline 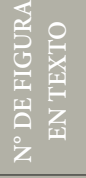 & $\begin{array}{l}n \\
n \\
\text { bi } \\
i\end{array}$ & 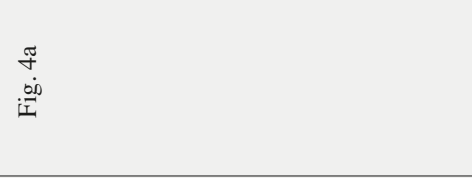 & $\begin{array}{l}\text { f } \\
\text { bi } \\
\text { i. }\end{array}$ & 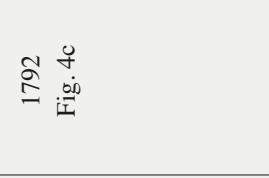 & $\stackrel{\vec{n}}{m}$ \\
\hline 20 & $\stackrel{+}{\stackrel{+}{\Xi}}$ & 号 & $\begin{array}{l}n \\
\stackrel{0}{0} \\
\stackrel{5}{0}\end{array}$ & $\begin{array}{l}m \\
\ddot{0} \\
\frac{0}{0} \\
\dot{0}\end{array}$ & $\begin{array}{l}m \\
\ddot{0} \\
\dot{0} \\
\dot{0}\end{array}$ \\
\hline 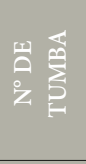 & 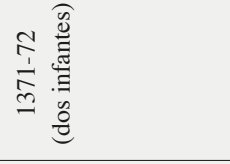 & 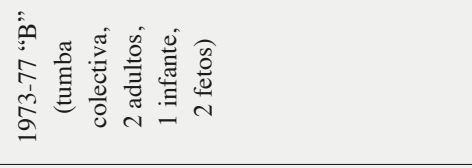 & 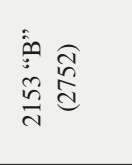 & $\stackrel{\infty}{\infty}$ & S: \\
\hline & 0 & - & an & $=$ & -7 \\
\hline
\end{tabular}




\begin{tabular}{|c|c|c|c|c|c|c|}
\hline 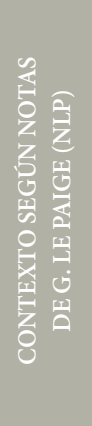 & & 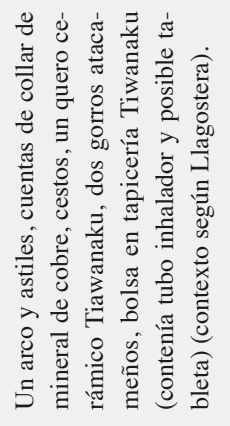 & 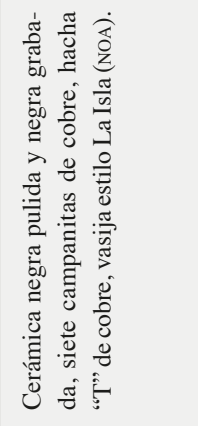 & 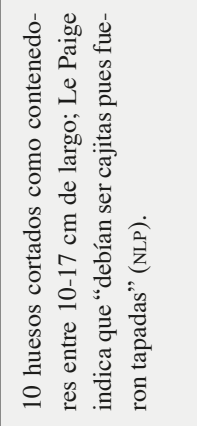 & 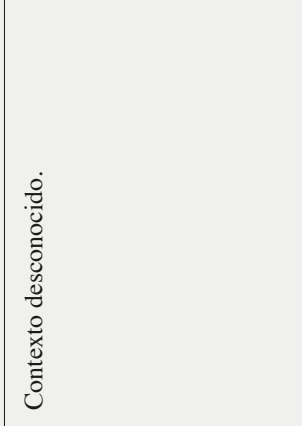 & 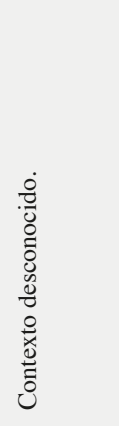 \\
\hline 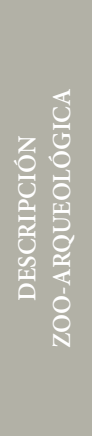 & 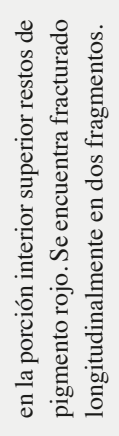 & 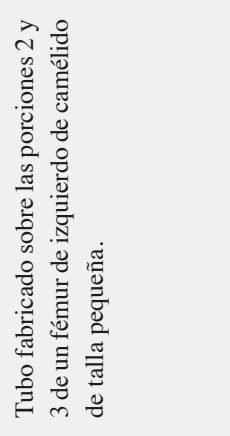 & 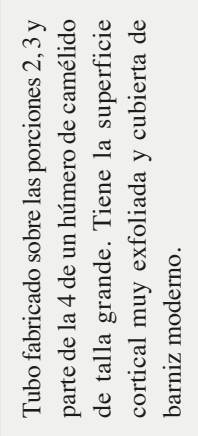 & 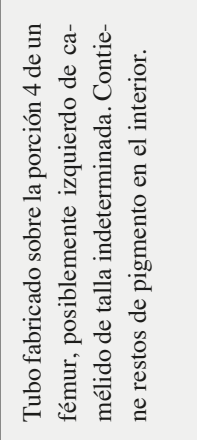 & 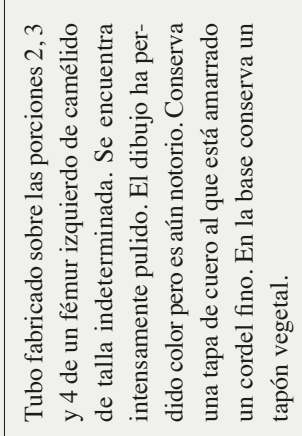 & 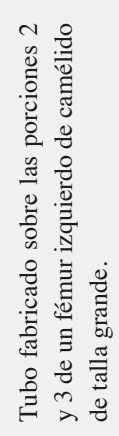 \\
\hline 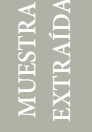 & & is & is & is & z & is \\
\hline 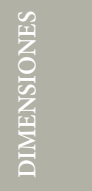 & & 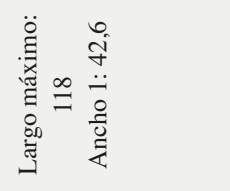 & 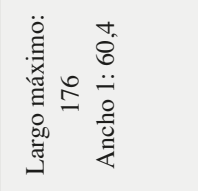 & 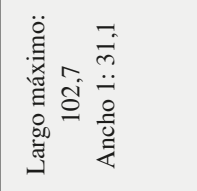 & 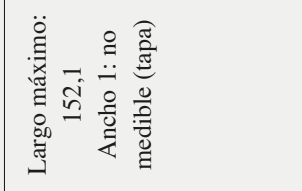 & 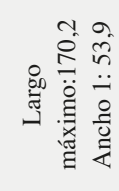 \\
\hline $\begin{array}{l}\frac{4}{4} \\
\text { of } \\
0 \\
0 \\
0 \\
0\end{array}$ & & 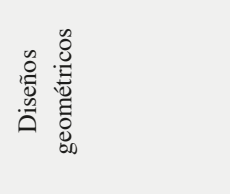 & 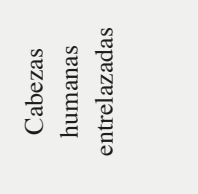 & 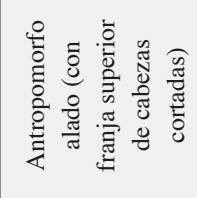 & 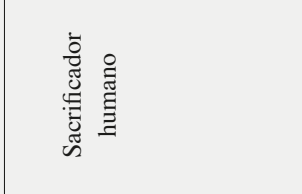 & 产 \\
\hline 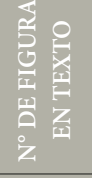 & & 6 & & 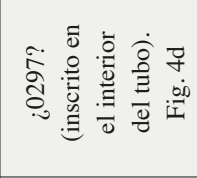 & $\begin{array}{l}0 \\
0 \\
\text { Di } \\
\mathbf{I}\end{array}$ & \\
\hline ind & & $\begin{array}{l}m \\
\ddot{0} \\
\frac{0}{0} \\
\text { in }\end{array}$ & 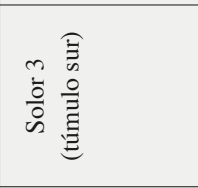 & $\begin{array}{l}\tilde{m} \\
\stackrel{0}{0} \\
\dot{0} \\
\tilde{n}\end{array}$ & $\begin{array}{l}ت \dot{\tilde{\Xi}} \\
\approx \\
\approx \\
\text { क }\end{array}$ & 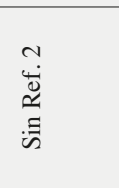 \\
\hline 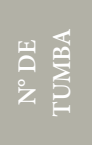 & & ฮี & 孛 & 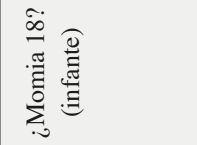 & 岂 & 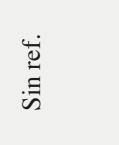 \\
\hline & & $\rightarrow$ & $\triangle$ & - & $\exists$ & $=$ \\
\hline
\end{tabular}




\section{ANÁLISIS ZOOARQUEOLÓGICO}

Los materiales fueron analizados en orden a identificar sus características anatómicas, procedencia taxonómica, técnica de elaboración y características métricas. Para la diferenciación de variables anatómicas y taxonómicas, se utilizaron atlas anatómicos especializados (Pacheco et al. 1986, Sierpe 2015). Para el registro de las variables métricas se utilizó un calibre digital marca Truper. Las medidas seleccionadas incluyeron: largo máximo, ancho 1, 2, 3, 4 y 5, dividiendo la extensión de la pieza en puntos equivalentes y espesores (cuatro medidas) en ambos extremos de los tubos. Las medidas fueron tomadas en milímetros a un decimal.

Los tubos fueron construidos sobre la diáfisis de huesos largos de camélidos sudamericanos, considerando individuos de diferentes grupos de tamaños, en los cuales se han agrupado dichos camélidos en la literatura especializada (Cartajena et al. 2007). Para su elaboración se utilizaron diferentes porciones del cilindro diafisario de huesos largos (húmero y fémur). En un número importante (más del 50\% de los tubos) se prefirieron los segmentos 2, 3 y 4 de las diáfisis, de acuerdo al esquema de segmentación de huesos largos propuesto por Saladié et al. (2011). Esta selección dice relación con el aprovechamiento de al menos la parte distal de la tuberosidad deltoidea en el caso de los húmeros, y de la parte distal del trocánter menor en los fémures (tabla 1). La morfología resultante de la selección de estos hitos es troncocónica, aprovechando un rasgo anatómico específico y de morfología similar en ambos huesos, que dejaba un "pico" en el tubo para vaciar su contenido.

En términos de manufactura, la totalidad de los artefactos parece hacer seguido un patrón de trabajo similar, correspondiente al corte o marcado perimetral de la diáfisis de los huesos. Una vez obtenido el tubo, se procedió a un intenso pulimento de las superficies y de limpieza (remoción de médula, grasa y otros residuos) para un posterior acabado final que varía de acuerdo al tratamiento de superficie de los tubos: a) aplicación de pintura para el dibujo de motivos, b) pulido, c) bruñido, d) grabado por incisión, e) grabado en alto relieve.

\section{ANÁLISIS QUÍMICO DE RESIDUOS}

El análisis químico orgánico de los residuos presentes en la muestra se realizó por cromatografía de gases acoplada a espectrometría de masas (CG-EM). Se sometieron a análisis 24 artefactos que en una inspección visual mostraron residuos adheridos en su interior. Los residuos fueron extraídos mediante un cuidadoso raspado de la superficie interna del artefacto con un bisturí previamente sanitizado con alcohol isopropílico. Para su análisis, estos residuos fueron sometidos a extracción sólido-líquido, siguiendo el protocolo de Echeverría et al. (2014) modificado, que conduce a extractos orgánicos (clorofórmico y metanólico). La técnica de CG-EM fue aplicada en dos modalidades: i) barrido completo de iones (вСІ), que monitorea todos los iones de la muestra en un rango entre $m / z 50$ y 500 , y que tiene como ventaja producir espectros de masas que pueden ser comparados con una base de datos y con la información disponible en literatura para su identificación, y ii) monitoreo selectivo de iones (MSI), que analiza iones de moléculas específicas previamente seleccionadas. Tomando en consideración estos parámetros, el análisis por UCN fue orientado hacia la búsqueda de los principales iones de alcaloides encontrados en restos bioarqueológicos y parafernalia alucinógena arqueológica de Chile y Argentina: nicotina $(m / z 84$ y 133$)$ dimetiltriptaminas ( $N, N$-dimetiltriptamina: $\mathrm{m} / z 58$ y 130; 5-metoxi- $N, N$-dimetiltriptamina: $m / z 58$ y 218 ; 5-hidroxi- $N, N$-dimetiltriptamina: $m / z 58$ y 146 ) (Echeverría \& Niemeyer 2013, Carrasco et al. 2015, Gili et al. 2016, Gili et al. 2017, Niemeyer et al. 2018).

Los resultados de los análisis químicos por cg-em de los extractos orgánicos de las muestras de los tubos contenedores pintados de SPA empleando en ambas modalidades (BCI y MSI), no mostraron indicios de las triptaminas diagnósticas para las especies Anadenanthera colubrina sp. reportadas como usadas en las prácticas inhalatorias a nivel regional (Gili et al. 2016), i.e., $N, N$-dimetiltriptamina (DMT), 5-metoxi- $N, N$ dimetiltriptamina (5-MeO-Dмт), 5-hidroxi- $N, N$ dimetiltriptamina (5-OH-DMT), ni tampoco nicotina, el compuesto mayoritario del género Nicotiana, de reconocido uso en las prácticas fumatorias en la zona de estudio (Carrasco et al. 2015, Echeverría \& Niemeyer 2013, Niemeyer et al. 2018). En general, los compuestos orgánicos detectados en los residuos adheridos a los tubos contenedores analizados constituyen una matriz compleja conformada por compuestos atribuidos tanto a fuentes vegetales como animales sin vinculación taxonómica específica. 

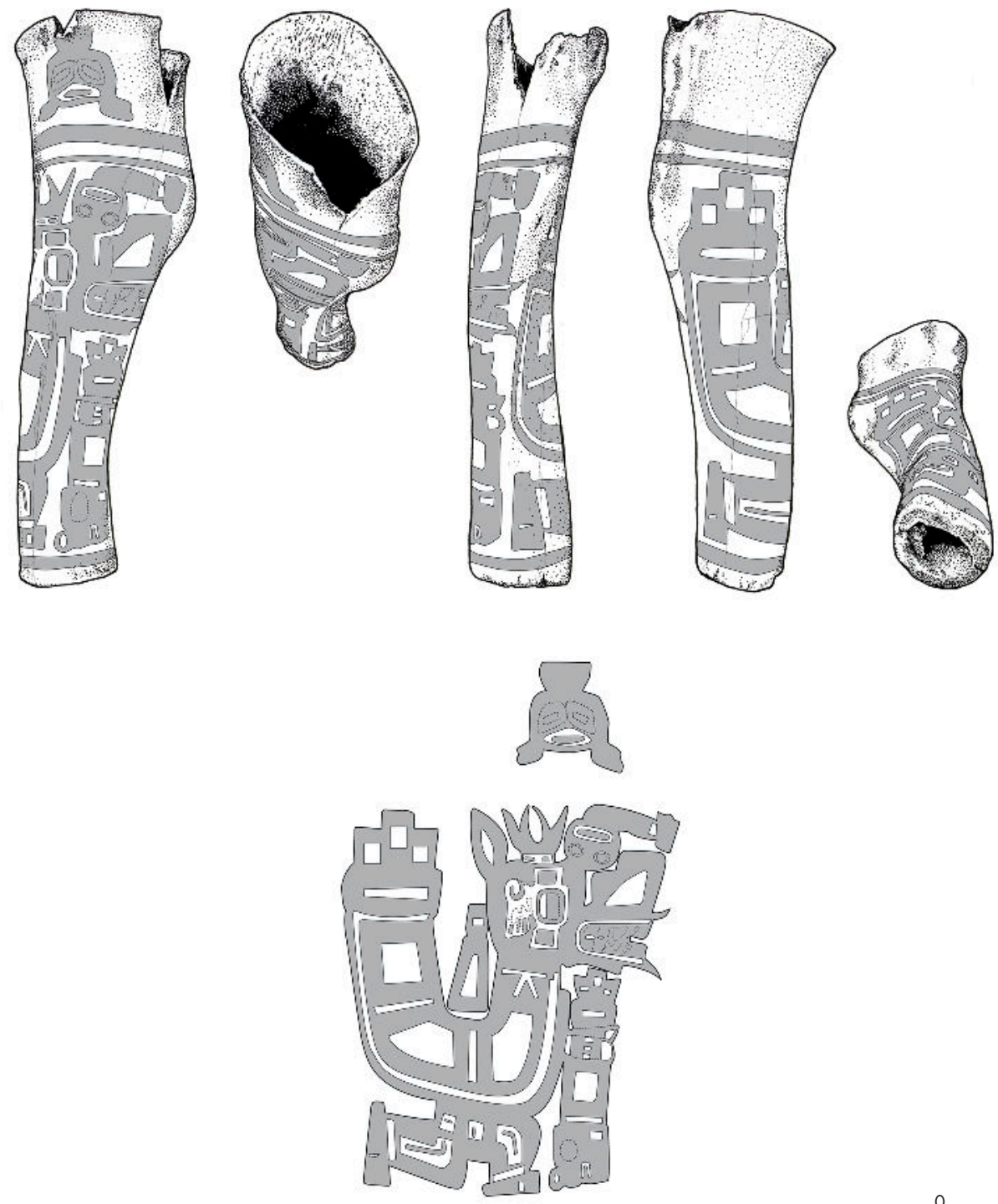

Figura 7. Tubo contenedor con Sacrificador-taruca de la tumba 2139-40 del cementerio Quitor 5. Colección del Museo Arqueológico R. P. Gustavo Le Paige S. J., IIAM-UCN. (Ilustración: Alex Olave). Figure 7. Container tube with taruca Sacrificer from grave 2139-40 at Quitor 4 cemetery. R.P. Gustavo Le Paige s. j. Archaeological Museum collection, IIAM-UCN. (Drawing: Alex Olave).

\section{ANÁLISIS ICONOGRÁFICO DE LOS TUBOS CON SACRIFICADOR TARUCA}

La variante taruca de El Sacrificador presenta particularidades que merecen ser analizadas en detalle. Para facilitar el análisis iconográfico, observaremos com- parativamente a los cuatro ejemplares de esta variante (figs. 7, 8, 9 y 10) en base a los siguientes segmentos: 1) cabeza, 2) tocado y adornos personales, 3) capa o cola, 4) ala o apéndice posterior, 5) extremidades inferiores y superiores, y 6) cetro. 

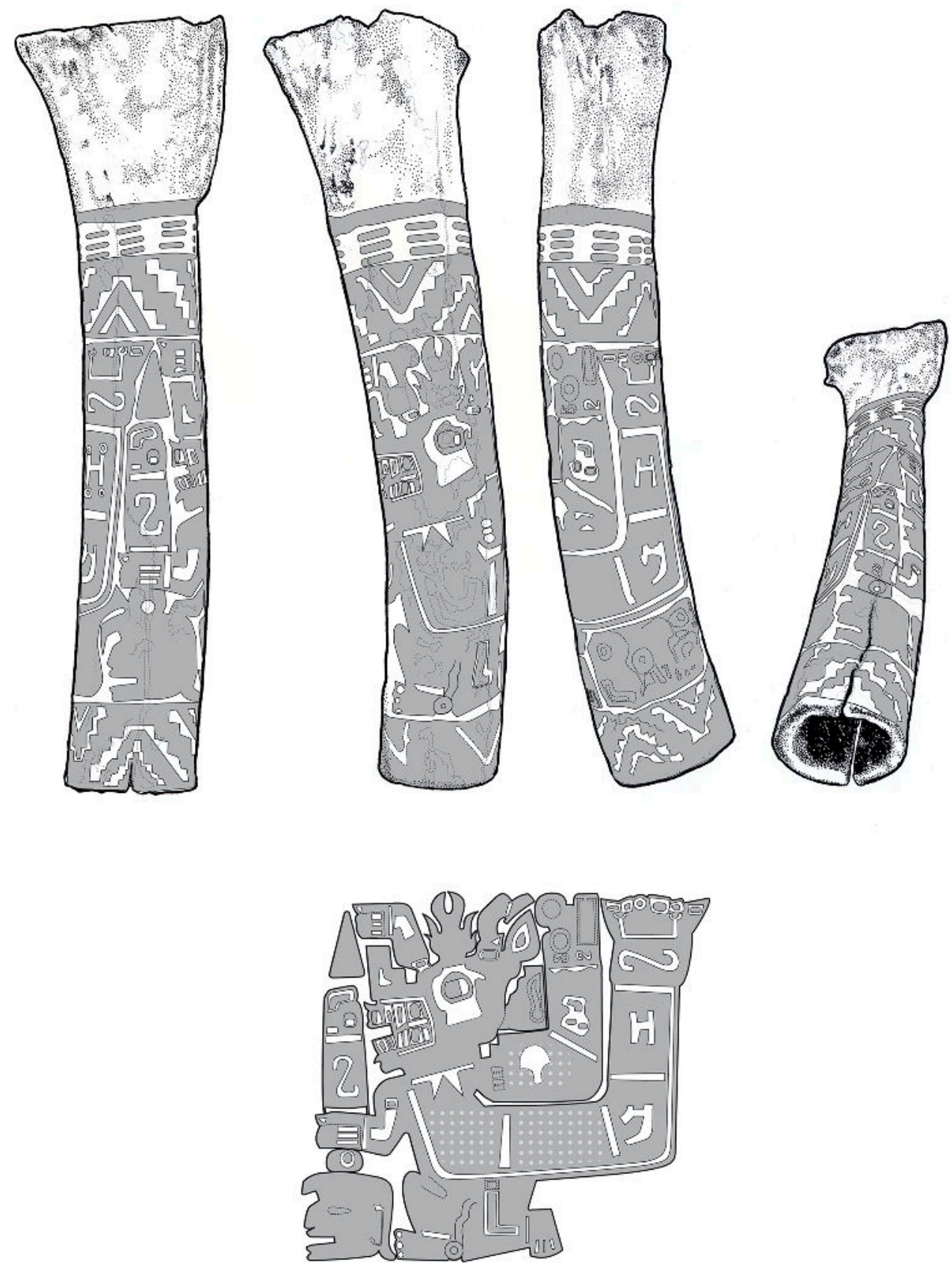

0

Figura 8. Tubo contenedor con Sacrificador-taruca de la tumba 1973-77 del cementerio Quitor 5. Colección del Museo Arqueológico R. P. Gustavo Le Paige S. J., IIAM-UCN. (Ilustración: Alex Olave). Figure 8. Container tube with taruca Sacrificer from grave 1973-77 at Quitor 4 cemetery. R.P. Gustavo Le Paige s. j. Archaeological Museum collection, IIAM-UCN. (Drawing: Alex Olave). 

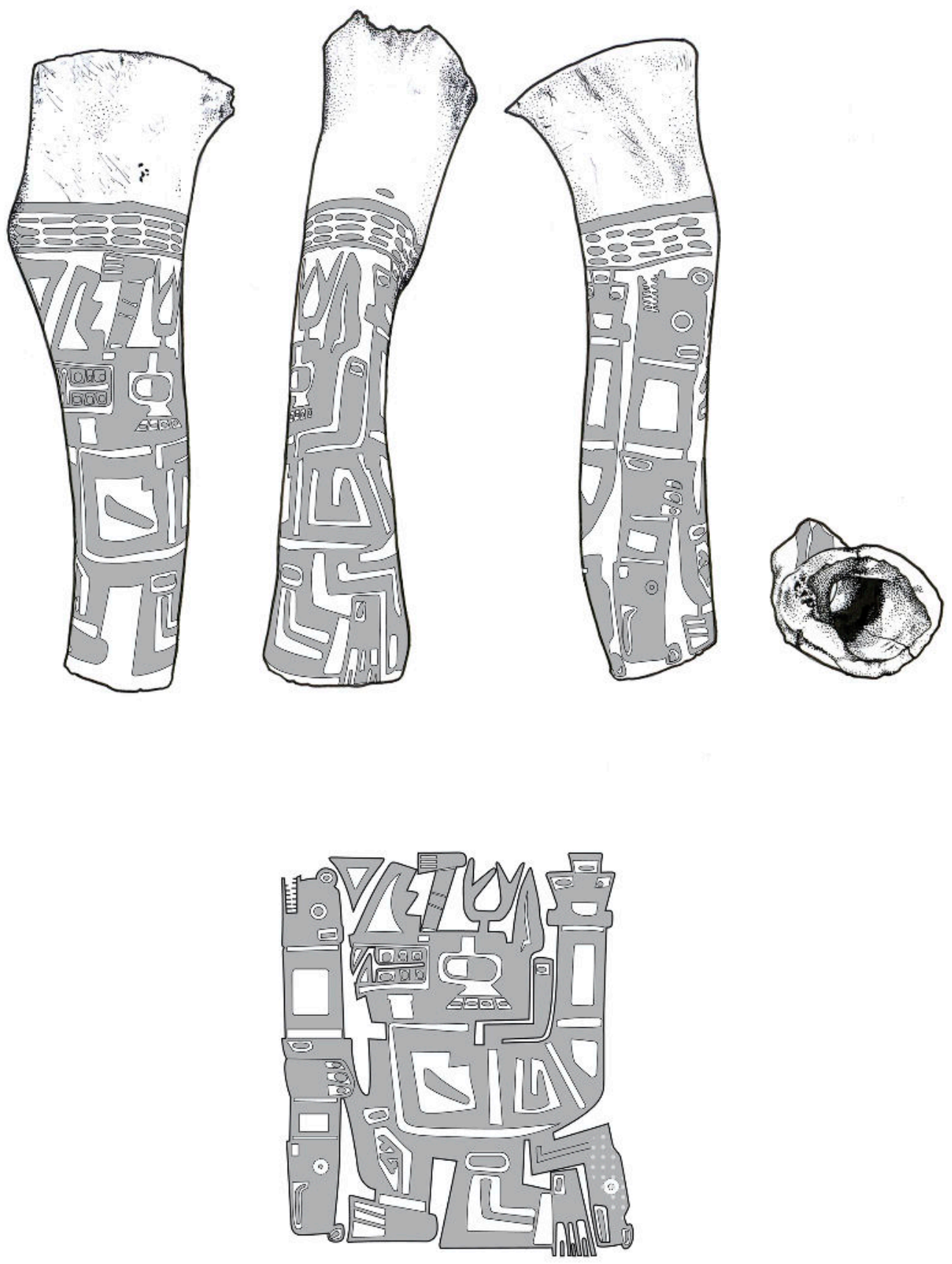

0 $3 \mathrm{~cm}$

Figura 9. Tubo contenedor "A" con Sacrificador-taruca de la tumba 2153 [2752] del cementerio Quitor 5. Colección del Museo Arqueológico R. P. Gustavo Le Paige S. J., IIAM-UCN. (Ilustración: Alex Olave). Figure 9. Container tube "A" with taruca Sacrificer from grave 2153 [2752] at Quitor 4 cemetery. R.P. Gustavo Le Paige S. J. Archaeological Museum collection, IIAM-UCN. (Drawing: Alex Olave). 

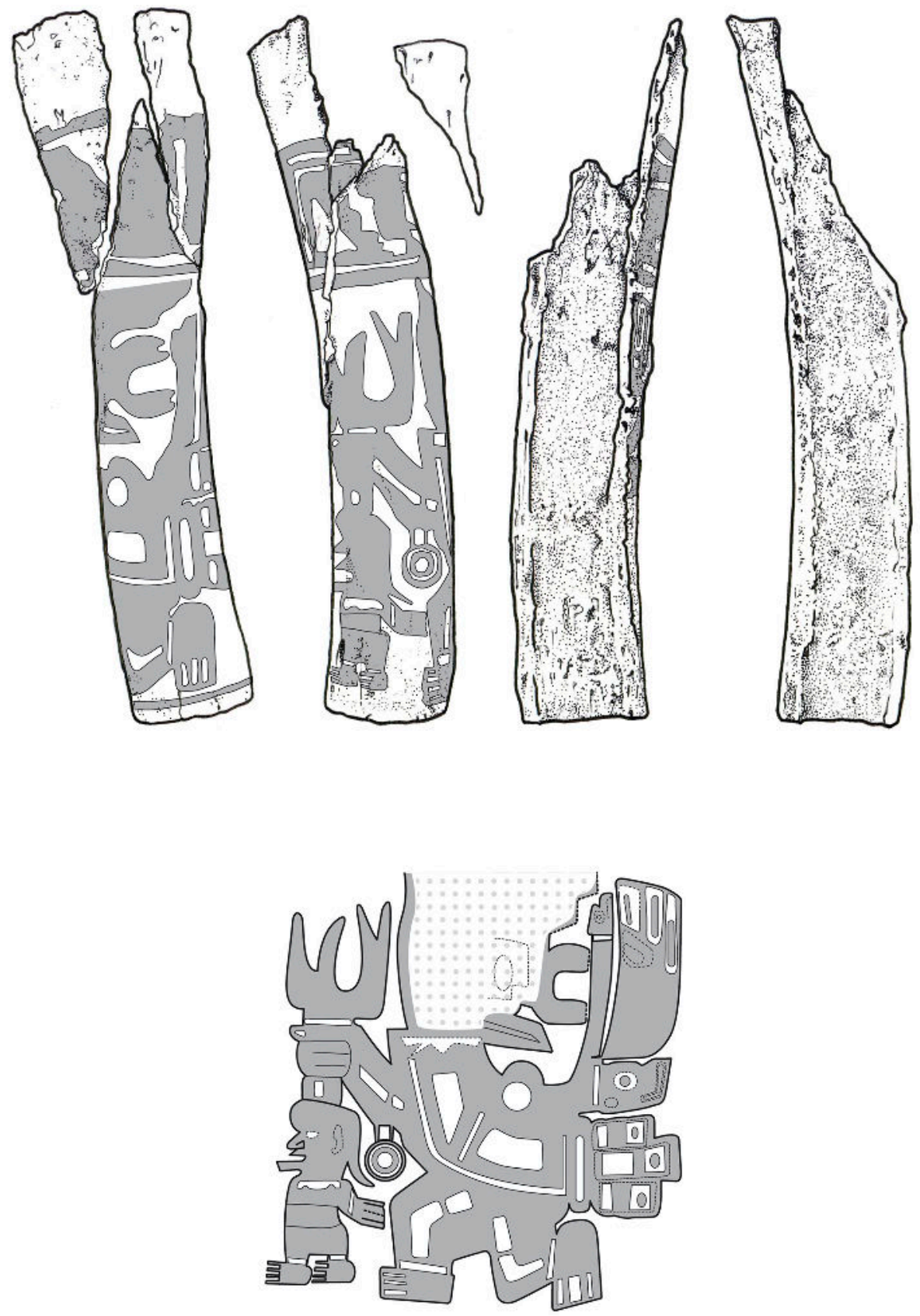

0

Figura 10. Tubo contenedor con Sacrificador-taruca de la tumba 3592 del cementerio Quitor 6. Colección del Museo Arqueológico R. P. Gustavo Le Paige S. J., IIAM-UCN. (Ilustración: Alex Olave). Figure 10. Container tube with taruca Sacrificer from grave 3592 at Quitor 4 cemetery. R.P. Gustavo Le Paige s. j. Archaeological Museum collection, IIAM-UCN. (Drawing: Alex Olave). 


\section{A) EJEMPLARES RECUPERADOS EN ATACAMA}

\section{Cabeza}

Mientras que en los ejemplares de las figuras 7, 8, y 9 la cabeza de El Sacrificador-taruca es representada de perfil -orientada indistintamente hacia la izquierda o derecha, dependiendo del caso particular de cada tubo-, en el cuarto tubo la cabeza mira hacia arriba (fig. 10). Consistentemente, las cuatro cabezas presentan narices escaleradas -constituidas por tres peldaños en el ejemplar 9 y 10 y por dos en los tubos 7 y $8-$ y orejas erguidas y aguzadas, de tamaño considerable. En cuanto a los elementos restantes del rostro, de aquí en adelante nos referiremos exclusivamente a las figuras 7,8 y 9 , esto debido al deterioro que presenta el rostro del Sacrificador-taruca del tubo 10, lo cual impide describirlo adecuadamente.

Por su parte, las bocas se representan entreabiertas, con la dentadura expuesta, y los labios sobresalen de la línea del perfil, curvándose hacia arriba y hacia abajo. El número y la composición de la dentadura es variable: nueve dientes para el ejemplar 8 y ocho para la figura 9, siendo dos de ellos colmillos entrecruzados en el caso del tubo 8. En cuanto al ejemplar 7, su estado de conservación imposibilita determinar con exactitud el número de dientes y la presencia o ausencia de colmillos. Aparte de la nariz escalerada, la dentadura expuesta y el énfasis en los labios, los ojos ovalados y bipartidos son un cuarto elemento común de los rostros pintados en los tubos 7, 8, y 9 . $^{3}$

\section{Tocado y adornos personales}

También denominados "coronas" o "crown/headdress" en la literatura especializada (Posnansky 1945, Torres 1984a y b, Isbell \& Knobloch 2008, entre otros), los tocados de los tubos 7, 8 y 9 se componen de un asta de venado -cuyos cuernos se distribuyen de manera simétrica en dos ramas- y por miembros del cuerpo humano cercenados. El mal estado de conservación de esta parte del tubo 10 impide, una vez más, distinguir los diversos elementos de su tocado: solo se aprecia el asta, y junto a este, la característica oreja puntiaguda de El Sacrificador-taruca.

Mientras que la cornamenta del ejemplar 7 -dispuesta sobre una base rectangular con formas geométricas similares inscritas en su interior- es acompañada por una cabeza antropomorfa frontal invertida de la cual emerge una extremidad inferior completa (fig. 7), en el tubo 9 se observa junto al asta una pierna humana con un pie de tres dedos (véase fig. 9). El tocado de El Sacrificador del tubo 8, por su parte, incluye un tercer elemento: observamos de izquierda a derecha, una extremidad superior, el asta en el centro, y una pierna que remata en un pie (fig. 8). La extremidad superior mencionada se compone de una mano empuñada con cuatro dedos y un antebrazo; en el interior de este último se observa una forma geométrica inscrita que sigue la línea del contorno. Finalmente, es importante agregar que estas extremidades humanas cercenadas enseñan adornos presumiblemente de metal a la altura del tobillo (¿tobillera?) y de la muñeca (¿brazalete?).

Entre los ornamentos personales, debemos mencionar tanto los adornos oculares como lo que parecen haber sido collares. Los primeros aparecen invariablemente en todos los ejemplares -no consideramos aquí el ejemplar 10 debido al problema de conservación ya señalado- $y$ los oculares presentan formas geométricas de diversa complejidad. Los adornos tipo collar, por su parte, se aprecian en el pecho de los sacrificadores-taruca de los tubos 7, 8 y 10; todos enseñan la forma de una letra $\mathrm{K}$ dispuesta de manera horizontal, lo que pareciera ser una variante simplificada del adorno denominado por Torres como "semicírculo con tres o más incisiones" (Torres 1984b, 1987).

\section{Capa o cola}

Partiendo desde abajo del mentón se despliega hacia la espalda de los cuatro personajes un elemento que hemos denominado "capa" o "cola". Si bien su forma es variable -mientras que en el tubo 7 se asemeja a una letra $\mathrm{U}$, en los demás ejemplares parece más bien una L espejada-, en todos los casos el extremo proximal de la capa o cola oculta la zona pectoral y ventral de los personajes representados; su parte central se extiende horizontalmente hacia atrás y su extremo distal remata en distintas variantes del elemento ondulado tripartito (Torres 1985), ${ }^{4}$ al cual llamaremos de aquí en adelante elemento tridígito. ${ }^{5}$ Otra característica común de estas capas/colas es que se encuentran subdivididas en distintos espacios que presentan inscritas figuras geométricas: un cuadrado y dos trapecios para el caso del tubo 7; dos motivos similares a una letra $\mathrm{H}$ en el 
ejemplar 8 (debido a problemas de conservación no ha sido posible identificar a las dos otras figuras restantes); un motivo escalerado, un gancho, un trapecio y un rectángulo en el tubo 9, un trapecio y un rectángulo en el ejemplar 10.

Finalmente, en tres de los ejemplares aquí analizados se constata la emergencia de apéndices desde distintos puntos de las capas/colas. En el tubo 8, el apéndice imita la forma en "L" espejada de la capa/cola, y ocupando el espacio comprendido entre esta y el cuello del personaje remata en una cabeza de felino en la que se aprecia ojo, nariz, boca y dos volutas S. En el ejemplar 9, este sigue la forma de una "L" invertida, emerge desde la parte inferior de la capa/cola y se despliega hacia abajo, rematando en una cabeza de felino, con ojo, nariz y boca claramente perceptibles. En el ejemplar 10, por su parte, observamos dos apéndices que surgen desde el lugar en que el elemento tridígito se une al resto de la capa/cola: mientras que el primero es pequeño y se reduce a una cabeza de pez, el segundo se extiende de manera perpendicular a la capa/cola y remata en una cabeza de pájaro.

\section{Ala o apéndice posterior}

Es en el ejemplar 10 donde el ala se observa con mayor claridad. Esta se ubica en el espacio comprendido entre los dos apéndices emergentes de la capa/cola arriba mencionados, y en su extremo superior se aprecian tres formas semi-rectangulares que podrían representar plumas. Proponemos que en los ejemplares 7 y 8 el ala se representa de manera simplificada, adoptando en ambos casos una forma semi-triangular ubicada inmediatamente detrás de la nuca/cuello del personaje representado. En el tubo 9, por su parte, no se observa la presencia de ala.

\section{Extremidades superiores e inferiores}

Ambos tipos de extremidades emergen desde abajo de la capa/cola, y tal como adelantáramos, enseñan en el interior formas geométricas inscritas siguiendo la línea de contorno de la figura. Las extremidades inferiores son representadas en posición genuflexa; con posibles tobilleras (similares a las de las piernas cercenadas que forman parte de los tocados), y con excepción del tubo 7 , los pies enseñan tres dedos. En cuanto a las extremidades superiores, en cada ejemplar se observa un solo brazo con su respectiva mano; estas siempre presentan cuatro dedos, y en las muñecas de los sacrificadores de los tubos 7 y 8 apreciamos posibles brazaletes.

\section{Cetro}

Los cuatro personajes empuñan cetros constituidos por distintos elementos que serán descritos a continuación, desde el extremo superior al inferior. El cetro del ejemplar 7 enseña un elemento tridígito, un rectángulo concéntrico y una cabeza de felino de perfil en la que se destaca nariz, boca, ojo, y un pequeño cuadrado ubicado en el sitio donde debiera comenzar el cuello del animal representado. El cetro del ejemplar 8, por su parte, presenta una cabeza de pez mirando hacia arriba en la que se observa ojo, boca y el pequeño cuadrado señalado para el caso anterior, así como una voluta $\mathrm{S}$ dentro de un rectángulo, un círculo concéntrico y una cabeza antropomorfa de perfil en la que se señalan rasgos faciales y el cabello. El cetro del tubo 9, en tercer lugar, se compone de una cabeza de felino en la que aprecia dentadura expuesta, ojo, nariz y oreja, así como dos rectángulos concéntricos consecutivos y una segunda cabeza de felino sin dentadura visible. Finalmente el tubo 10 enseña una cornamenta de venado, un óvalo concéntrico y una figura antropomorfa representada de perfil, de la cual se distinguen con claridad ojo, nariz, boca, oreja, mentón prominente (¿tembetá?), cabello, brazalete, tobillera, collar, faja en la cintura y brazos atados en la espalda. ${ }^{6}$

\section{B) TUBOS EXTRA-SALAR DE ATACAMA}

En la búsqueda de analogías para los diseños plasmados en los tubos excavados de contextos funerarios del salar de Atacama, hemos encontrado un reducido número de tubos de formato semejante y figuras de El Sacrificador en su variante taruca. Aquí hay que mencionar el tubo pintado proveniente de la cueva de Pulacayo (Escara, Potosí, Bolivia), hoy preservado en el Museo de Arte Indígena de Sucre (Agüero 2007, Cruz 2009) (fig. 11). ${ }^{7}$ Tuvimos acceso al mismo y relevamos su dibujo, lo cual ha permitido reconocer su pertenencia al círculo temático (Sacrificador-taruca) que se aprecia en los tubos exhumados en San Pedro de Atacama. Lo mismo ocurrió con el tubo 71.1878.8.35 de la colección del Musée du quai Branly, el cual constituye la contraparte en técnica de grabado en alto relieve del tema del Sacrificador (fig. 

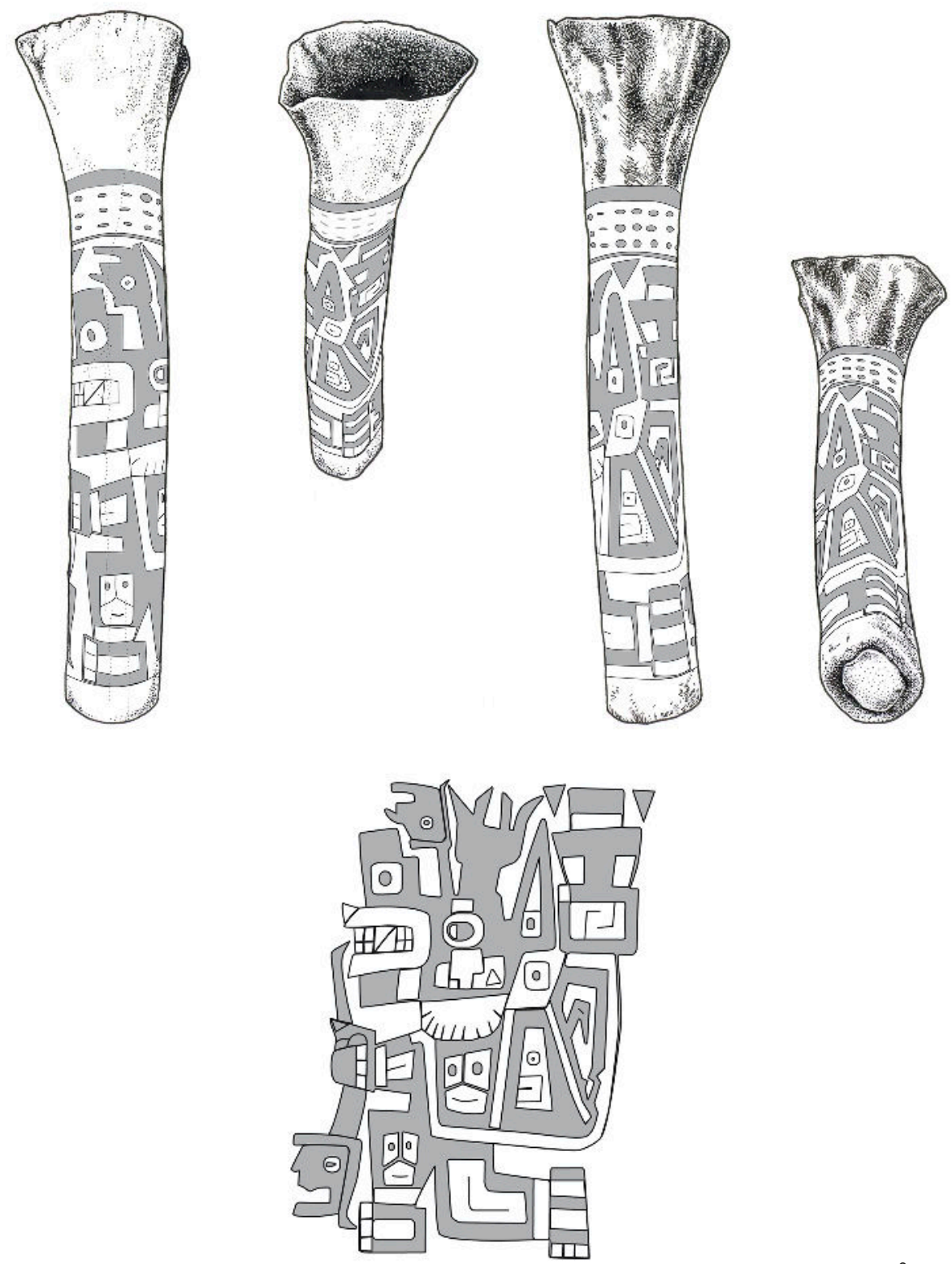

0

Figura 11. Tubo contenedor (PU-01) con Sacrificador-taruca proveniente de la cueva de Pulacayo, Bolivia. Colección AsuR, Sucre. (Ilustración: Alex Olave). Figure 11. Container tube (PU-01) with taruca Sacrificer from Pulacayo Cave, Bolivia. AsUR collection, Sucre. (Drawing: Alex Olave).

12). Este ejemplar es de especial importancia porque, por una parte, proviene de Tiahuanaco mismo, según el registro del museo parisino que incluye los datos de su donante, Théodore Ver, y por otra parte, el hecho de que sus diseños hayan sido grabados, pues de esta manera es evidencia de la existencia sincrónica de dos diferentes técnicas de manufactura durante el Período Medio en el centro-sur andino. ${ }^{8}$ 

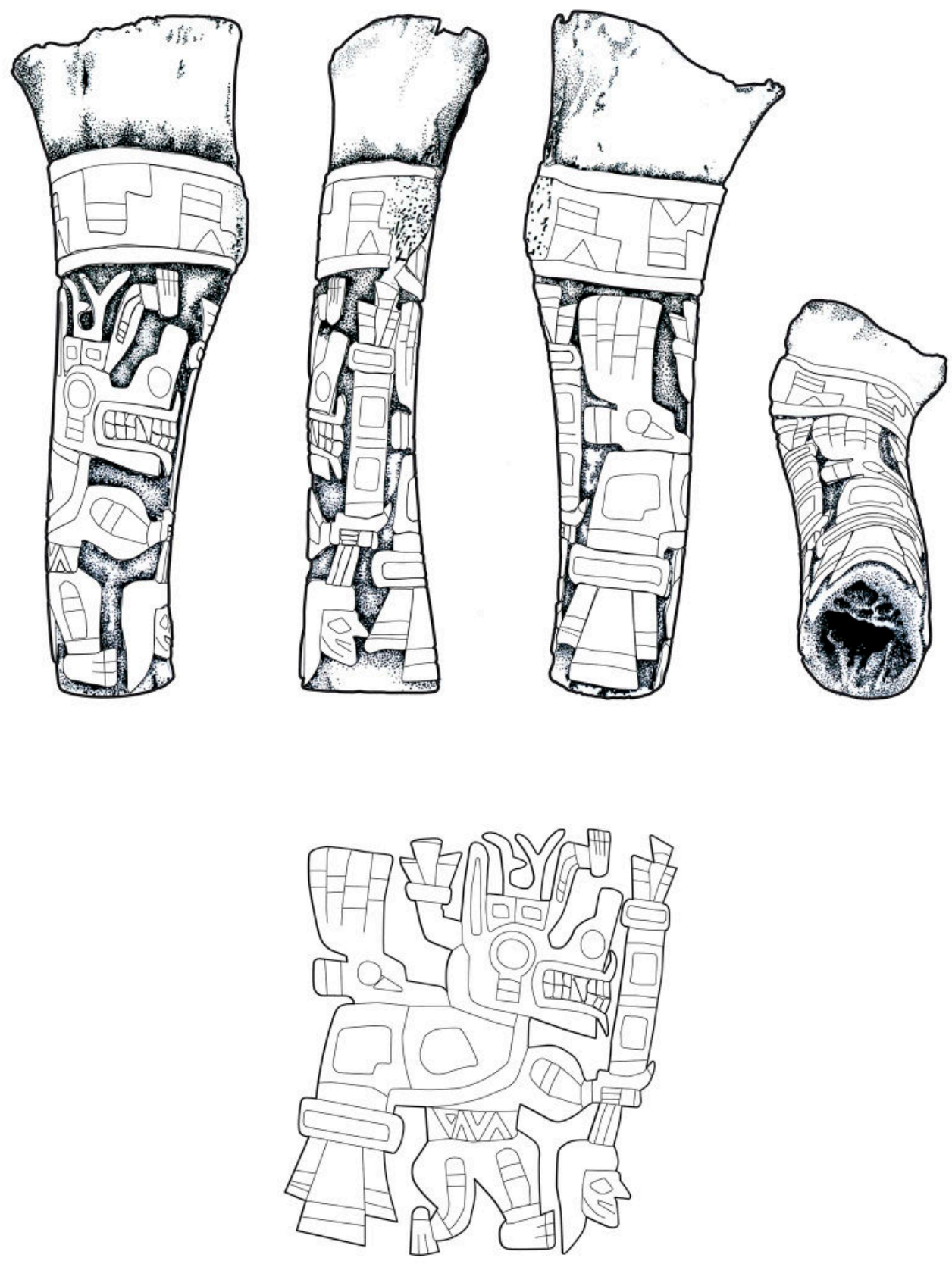

0

Figura 12. Tubo contenedor 71.1878.8.35 con Sacrificador-taruca proveniente de Tiahuanaco. Colección Musée du quai Branly, París. (Ilustración: Alex Olave). Figure 12. Container tube 71.1878.8.35 with taruca Sacrificer from Tiahuanaco. Musée du quai Branly collection, Paris. (Drawing: Alex Olave). 

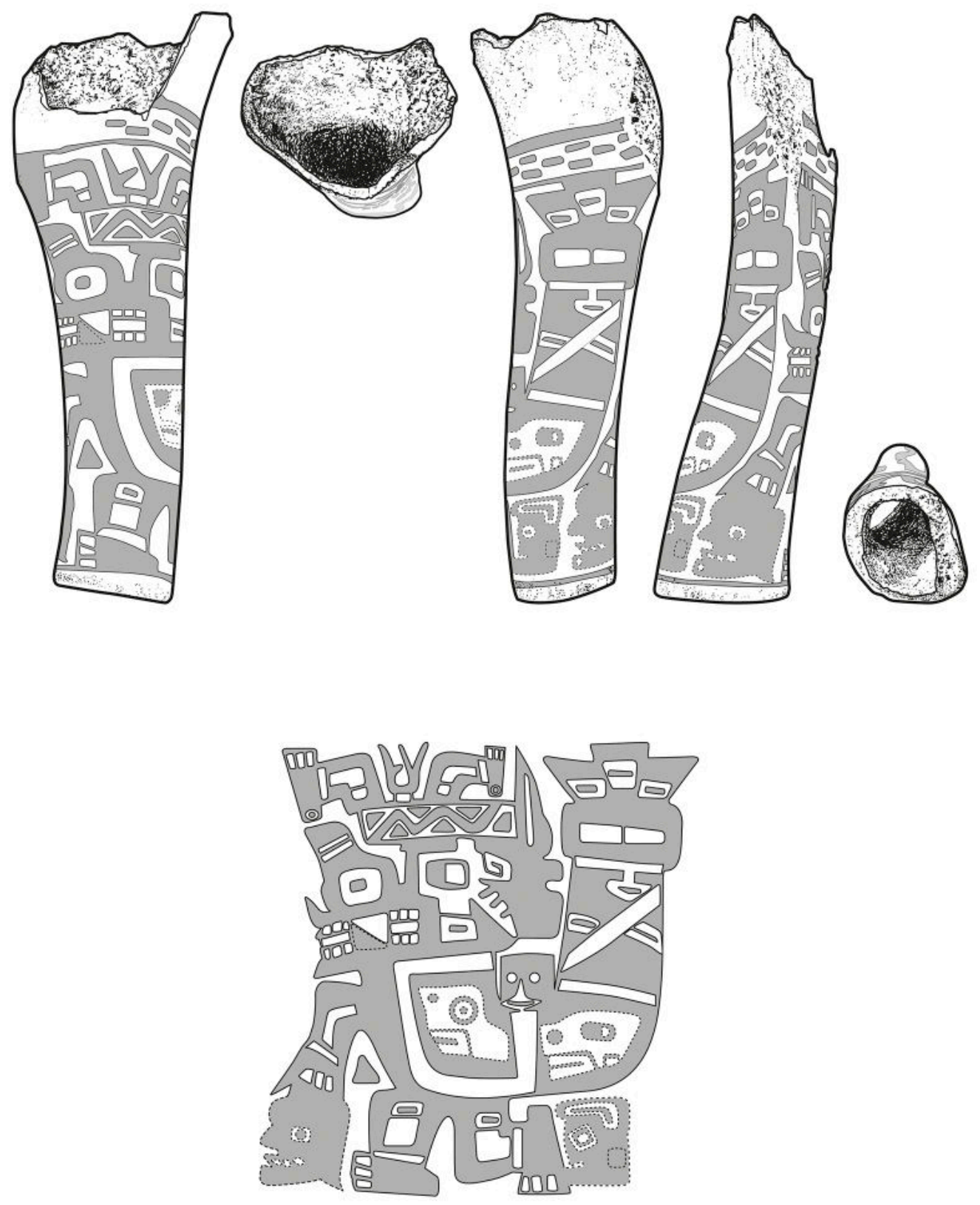

0 $3 \mathrm{~cm}$

Figura 13. Tubo contenedor сFв 3374a/716 [0002] con Sacrificador-taruca, sin proveniencia conocida. Colección Museo de Metales Preciosos Precolombinos, La Paz. (Ilustración: Alex Olave). Figure 13. Container tube CFB 3374a/716 [0002] with taruca Sacrificer, unknown provenance. Pre-Columbian Precious Metals Museum collection, La Paz. (Drawing: Alex Olave). 
El tercer caso análogo en términos iconográficos y técnicos es el del tubo pintado CFB 03374 (0002 ORG/716) de la colección del Museo de Metales Preciosos Precolombinos de La Paz, Bolivia (fig. 13). Desgraciadamente, su proveniencia exacta es desconocida. A continuación, analizaremos estos tres tubos con las imágenes de sacrificadores-taruca, siguiendo la secuencia de segmentos ya empleada para el caso de los tubos atacameños.

\section{Cabeza}

Tal como ocurre en el caso de los sacrificadores-taruca representados en los tubos excavados de contextos funerarios de los diferentes oasis de San Pedro de Atacama, la nariz de los ejemplares altiplánicos se estructura en base a dos peldaños, se destacan los labios, presentan dentadura expuesta (diez en el ejemplar de Pulacayo; fig. 11; catorce en los ejemplares del quai Branly, fig. 12 y el de La Paz, fig. 13, respectivamente, con los colmillos entrecruzados en el centro de las fauces), y -con excepción del tubo grabado de la figura 12- los ojos se representan bipartidos.

\section{Tocados y adornos personales}

Del mismo modo que en los ejemplares de las figuras $7,8,9$ y 10 , los tocados representados en los ejemplares altiplánicos se componen de un asta de venado y de diferentes partes del cuerpo humano. El tocado del Sacrificador-taruca del tubo de Pulacayo es el más sencillo de este grupo, pues junto a su cornamenta solo se observa una cabeza de perfil invertida (fig. 11). En segundo lugar, el tocado del tubo del quai Branly se asemeja al del ejemplar de la figura 7 , en cuanto incluye igualmente una pierna que remata en un pie de cuatro dedos, continúa con el asta de venado, aunque luego despliega hacia la parte posterior de la cabeza un elemento tridígito (situación excepcional en la muestra analizada (fig. 12). Es importante agregar en relación con este último tubo que la cornamenta del tocado descansa, del mismo modo que en el ejemplar 7 , en una base con rectángulos concéntricos. El tocado del ejemplar de La Paz, por su parte, presenta una base en forma de zigzag, sobre la cual se ubica el asta en el centro de dos piernas humanas con pies de tres dedos y un pequeño círculo concéntrico en el lugar del talón (fig. 13). En consonancia con lo observado para los ejemplares asociados a tumbas atacameñas, todas las extremidades inferiores que forman parte del tocado de los tubos altiplánicos enseñan tobilleras y formas geométricas inscritas siguiendo la línea del contorno exterior.

En cuanto a los adornos personales, los tres ejemplares aquí analizados presentan adornos oculares de formas geométricas de complejidad variable, y el ejemplar de Pulacayo exhibe un collar en forma semicircular (fig. 11), el que al igual que los collares de los tubos 7,8 y 10, corresponde al ya mencionado "semicírculo con tres o más incisiones” (Torres 1984b, 1985).

\section{Capa o cola}

Coincidiendo con lo constatado en relación con los ejemplares 7, 8, 9 y 10, los tres tubos altiplánicos presentan capas/colas, rematan en distintas variantes del elemento tridígito, e invariablemente la superficie se encuentra dividida en segmentos con motivos inscritos (figs. 11, 12 y 13). En el caso del ejemplar del quai Branly (fig. 12), la superficie de la capa/cola se divide en dos partes, cada una con un motivo semi-cuadrado inscrito en el interior. La capa/cola representada en el tubo de La Paz, por su parte, difiere de las demás ya que además de una forma geométrica, presenta inscritas tres cabezas presumiblemente antropomorfas, dos de perfil y una frontal (fig. 13). Finalmente, la capa/cola del ejemplar de Pulacayo, presenta cuatro espacios separados: mientras que en los dos más cercanos al elemento tridígito se observan formas geométricas, en los dos últimos se aprecian cabezas probablemente antropomorfas, una de perfil y la otra frontal (fig. 11).

\section{Ala o apéndice posterior}

Es en el ejemplar del quai Branly donde el ala se aprecia con mayor claridad (fig. 12). Esta se despliega por sobre la capa/cola y, de manera similar al ejemplar 10, presenta cuatro franjas verticales que simbolizarían plumas. Junto con ello, en la base del ala se observan dos formas geométricas - un círculo y un triángulo-, y un pequeño apéndice que surge hacia atrás. Los ejemplares de La Paz y Pulacayo, por su parte, no cuentan con ala, coincidiendo así con lo observado para la figura 9.

\section{Extremidades inferiores y superiores}

Al igual que con los ejemplares 7, 8, 9 y 10, en el caso de los tres tubos extra salar de Atacama, las piernas emergen desde abajo de la capa/cola, y enseñan en el interior 
formas geométricas que siguen la línea del contorno de la figura. En relación a esta última característica, el ejemplar de Pulacayo presenta una novedad, pues en la pierna anterior se aprecia una cabeza antropomorfa frontal en lugar de las figuras geométricas antes mencionadas (fig. 11).

\section{Cetro}

Contrariamente, y diferenciándose de los tubos excavados en Atacama, los sacrificadores-taruca representados en los tubos de Pulacayo y La Paz sostienen una cabeza antropomorfa de perfil que remplaza al cetro: mientras que en el caso de la figura 11, la cabeza cuelga desde una suerte de cuerda, en el segundo es asida directamente por el cabello (fig. 13). Cabe destacar que ambas cabezas enseñan ojos, nariz y boca entreabierta. Por su parte, el ejemplar del quai Branly, sí sostiene un cetro. Este es semejante al patrón observado para los cetros de los sacrificadores representados en los tubos atacameños, conformándose de un elemento tridígito con base subrectangular concéntrica y dos rectángulos concéntricos, así como de una cabeza antropomorfa de perfil, de la cual se aprecian cabello, nariz, ojos y boca (fig. 12).

En suma, del análisis realizado se desprende que en conjunto los tubos exhumados en Atacama y los ejemplares de tierras altas presentan similitudes tanto en el patrón de distribución de los diseños, ${ }^{9}$ como en la temática iconográfica. Las diferencias observadas son mínimas, y consisten fundamentalmente en que los tubos altiplánicos presentan cabezas cortadas dentro del cuerpo o en los segmentos interiores de la cola o capa, así como el reemplazo del cetro completo mediante cabezas cortadas. Estas divergencias no resultan relevantes, ya que igualmente hacen referencia al sacrificio. Todos los demás rasgos, tales como la representación de perfil, la postura corporal genuflexa, el uso de tocado, adornos personales, etc., resultan ser compartidos.

\section{DISCUSIÓN Y COMENTARIOS FINALES}

Tal como ha sido expuesto, en los tubos de Pulacayo (fig. 11), quai Branly (fig. 12) y de La Paz (fig. 13) se identificó la imagen de El Sacrificador con el atributo de venado en la misma configuración que presentan los cuatro tubos encontrados en Atacama. Es así como, en los siete ejemplares estudiados, el tocado de los personajes incluye cuernos de venado y diversas partes desmembradas del cuerpo humano, ${ }^{10}$ identificándose las siguientes variables: a) pierna completa con pie (figs. 8 , 9,12, y 13); b) cabeza desde la cual surge una pierna (fig. 7); c) cabeza sola (fig. 11), y d) antebrazo unido a mano (fig. 8). Como una forma de reforzar su carácter de sacrificador, cinco de los siete personajes sostienen en las manos (o desde el remate del cetro) cabezas o cuerpos humanos completos (figs. 8, 10, 11, 12, 13, respectivamente), ${ }_{1}^{11} \mathrm{y}$ en dos de los tres ejemplares altiplánicos se observan pequeñas cabezas, tanto frontales como de perfil, inscritas en distintas partes del cuerpo o de la cola/capa (figs. 11 y 13 ). ${ }^{12}$

Como ya señalamos, las similitudes entre tubos intra y extra salar no se limitan solo a los atributos que identifican al ícono como sacrificador y -al mismo tiempo- como venado. Es importante recalcar que en los siete tubos que constituyen nuestro corpus se advierten rasgos y soluciones visuales muy semejantes, situación que nos permite plantear que, además de compartir un mismo "mensaje" (el de El Sacrificador variante taruca), este es expuesto de la misma manera en cada tubo. Como ejemplo de ello, podemos señalar la configuración de los dedos de la mano con el pulgar sobredimensionado, o las fauces con el detalle de sus remates curvados hacia arriba, por solo mencionar algunos de los más llamativos.

En relación con las semejanzas iconográficas que Le Paige señaló entre tubos contenedores y tabletas para inhalar, entregamos aquí información actualizada. Esta deriva del análisis comparativo realizado con más de 600 tabletas para inhalar que posee el IAAM, entre las cuales hemos registrado un número menor de tabletas que presentan sacrificadores-humanos o sacrificadores-felinos. ${ }^{13}$ En dicho conjunto de tabletas se observa el mismo patrón general de representación que hemos analizado para los tubos contenedores: figuras de perfil con tocados y adornos personales, así como con capa o cola, ala y cetro, exhibiendo los atributos de la decapitación (hacha y cabeza cortada) de forma más o menos explícita, en ocasiones con los dos elementos juntos en las manos, a veces solo uno (hacha o cabeza). Alternativamente, la alusión al sacrificio humano solo se da por medio del cetro que remata en cabeza humana cortada, y solo en tres de las 15 tabletas mencionadas, la incorporación de miembros cercenados del cuerpo humano ocurre a través de los tocados de los sacrificadores, tal como ya hemos visto en el caso de los tubos 


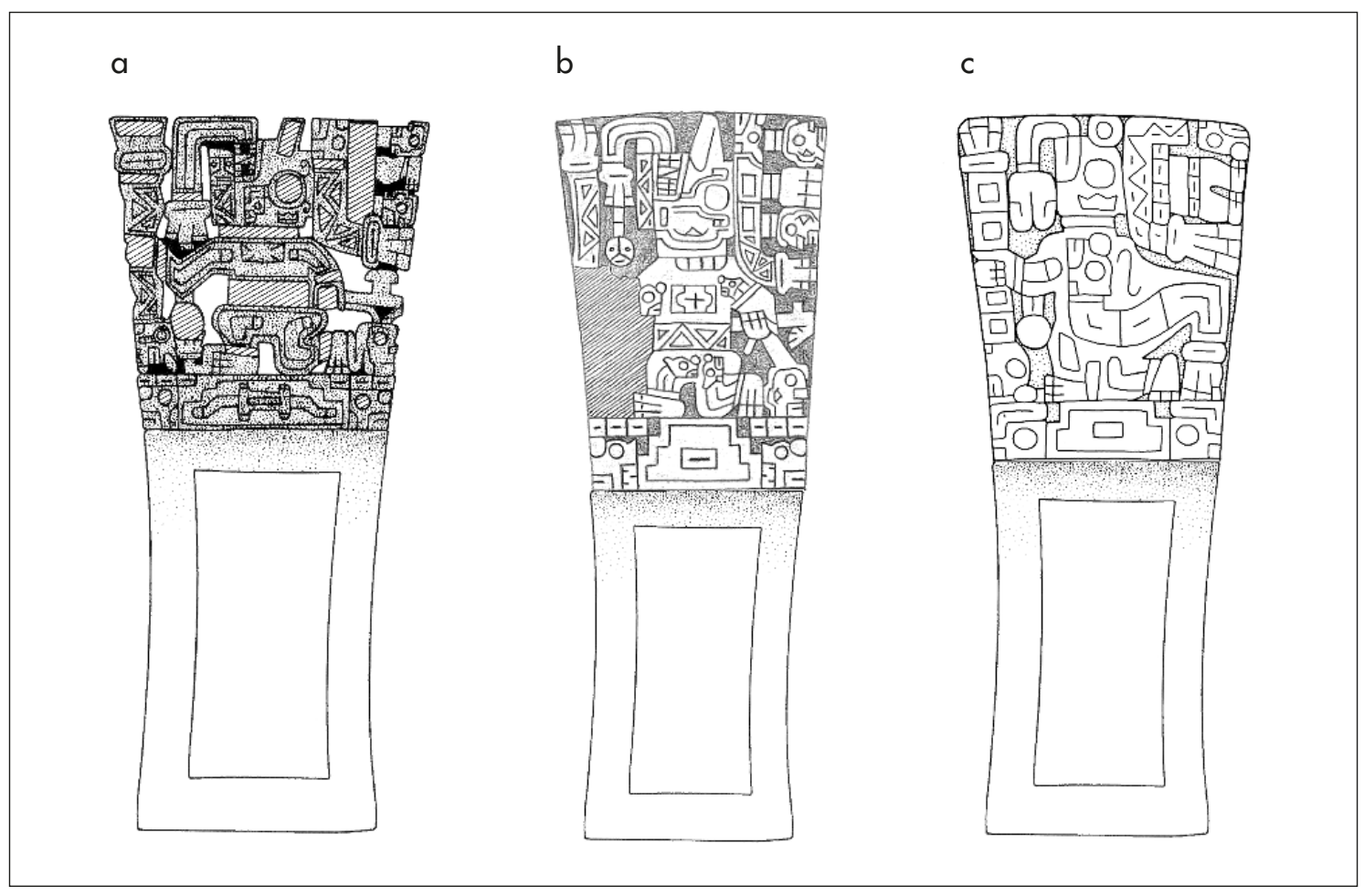

Figura 14: a) tableta para inhalar de la tumba 107 de Solcor 3 (modificada de Llagostera 1995: fig. 11b); b) tableta para inhalar de la tumba 3613 de Quitor 6 (modificada de Llagostera 2006: fig. 11a; c) tableta para inhalar de la tumba 4008 de Coyo Oriente (modificada de Torres \& Repke 2006: fig. 8c). Colección del Instituto de Investigaciones Arqueológicas y Museo R. P. Gustavo Le Paige S. J., IIAMUCN. (Ilustración: Alex Olave). Figure 14. a) Snuff tray from grave 107 at Solcor 3 (modified by Llagostera 1995: fig. 11b); b) Snuff tray from grave 3613 at Quitor 6 (modified by Llagostera 2006: fig. 11a); c) Snuff tray from grave 4008 at Coyo Oriente (modified by Torres \& Repke 2006: fig. 8c). R.P. Gustavo Le Paige s. j. Archaeological Museum collection, IIAM-UCN. (Drawing: Alex Olave).

contenedores excavados en Atacama. ${ }^{14}$ Como ejemplo, hay que mencionar al Sacrificador-humano con nariz prominente de la tableta de la tumba 107 de Solcor 3 , en cuyo tocado se aprecian dos cabezas cortadas y una pierna completa, además del hacha y otra cabeza que figuran entre los elementos que enseña (fig. 14a; Llagostera 2006: 85). Asimismo, la tableta de la tumba 3613 de Quitor 6 muestra dos cabezas humanas en el tocado del sacrificador igualmente humano con nariz prominente representado en ella, el cual sostiene hacha y cabeza cortada en una misma mano (fig. 14b; Llagostera 2006: fig. 11b). El tercer caso es el de la tumba 4008 de Coyo Oriente, en cuya tableta se aprecia un Sacrificadorfelino con medio cuerpo humano dispuesto en el tocado (fig. 14c; Llagostera 2006: 85). Por lo mismo, parece posible plantear en relación con las representaciones de sacrificadores-taruca un mayor énfasis en la figuración de miembros del cuerpo humano cercenados, tanto en el tocado y en el cetro, como en el cuerpo mismo. No deja de ser significativo que sean solo tres las tabletas con representación de sacrificadores (humanos y felinos), en las que aparecen miembros del cuerpo humano haciendo parte de sus respectivos tocados.

De esta manera, se han identificado elementos compartidos por las tres variantes de sacrificadores representados en los tubos, situación que permite suponer que la manufactura de este tipo de artefacto debió estar regida estrictamente, y pautada al mismo tiempo por convenciones culturales fuertemente arraigadas. En suma, tomando como base el análisis de todos los ejemplares, tanto de los tubos contenedores encontrados en Atacama, como los provenientes del altiplano boliviano, podemos establecer que el atributo exclusivo de la faceta taruca de El Sacrificador son las astas en el tocado, puesto que la nariz escalerada, la dentadura expuesta y los colmillos entrecruzados, así como los instrumentos que connotan el sacrificio humano -hacha y cabeza cercenada- son atributos compartidos con sus 


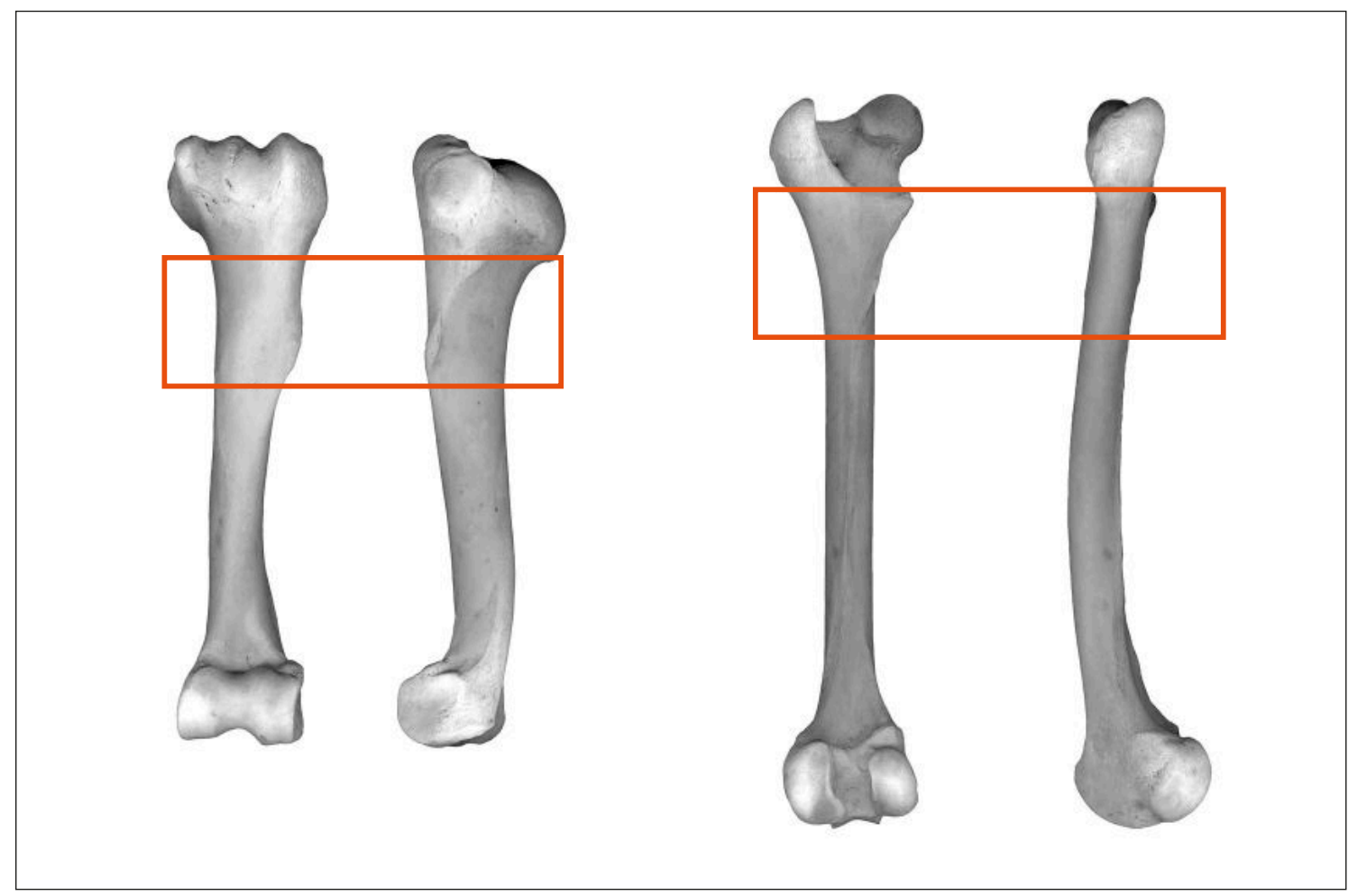

Figura 15. Porción 2 de húmero (izquierda) y fémur (derecha). Se puede apreciar la tuberosidad deltoidea y el trocánter menor respectivamente. (Imagen modificada de Sierpe 2015). Figure 15. Part of humerus (left) and femur (right). The respective deltoid tuberosity and the minor trochanter can be observed. (Image modified by Sierpe 2015).

dos otras facetas, la humana y la felínica. Frente al hecho de que no ha sido posible detectar en ningún artefacto de la parafernalia inhalatoria el atributo específico de los cuernos del Sacrificador-taruca, nos planteamos la siguiente interrogante: ¿dicha configuración podría haber estado reservada para el soporte exclusivo de los tubos contenedores pintados o grabados?

Por otra parte, el contexto del tubo de Pulacayo muestra similitudes adicionales con los ejemplares atacameños (tabla 1), en cuanto proviene de un ajuar funerario que, junto con diversos bienes de prestigio, se encontró además asociado a componentes del equipo inhalatorio, en este caso a un tubo para inhalar de hueso de ave. Entre dichos bienes -que por sí mismos marcan importantes diferencias respecto de ajuares más simples en número y calidad de artefactos- figuraba una magnífica túnica con iconografía de El Sacrificador-felino, un brazal y un brazalete de metal, un collar de cuentas de mineral de cobre, entre otros (Agüero 2007, Cruz 2009, Registro del Museo de Arte Indígena; Lechtman et al. 2010). En paralelo, los contextos de los tubos analizados provenientes de Atacama evidencian haber incluido tanto bienes conspicuos (collares de cuentas de mineral de cobre, adornos personales y hacha de metal) como foráneos (cerámica no local), y prácticamente todos muestran asociación con artefactos propios del equipo inhalatorio (tabla 1). Aquí hay que destacar además la situación excepcional de dos entierros del cementerio Quitor 5, cuyos ajuares incluían simultáneamente dos tubos pintados (tumba colectiva 1973-77 y tumba individual 2153). En ambos casos se estableció que la iconografía se da en par entre un Sacrificador-taruca y un felino antropomorfizado (tabla 1; fig. 4a con fig. 8; fig. 4b con fig. 9).

Desde el punto de vista del proceso de manufactura -revelado en los tubos por medio del análisis zooarqueológico- este parece seguir un patrón similar en el conjunto total de piezas, el cual dice relación con una fase inicial de selección de las unidades anatómicas utilizadas para posteriormente seccionar los segmentos especificados previamente, probablemente a través del surcado perimetral para lograr un corte preciso (fig. 15). Una vez obtenidas las formas base, se procedió a 
pulirlas, ocultando las huellas de manufactura. Luego del pulimento inicial, los tubos pudieron ser sometidos finalmente a diferentes técnicas: pulido completo, aplicación de pintura, grabado con incisiones leves o profundas o recubrimiento con cuero u otros elementos. En nuestra revisión del tema realizada en colecciones de otros museos, tanto de Chile como del extranjero, nos encontramos con que para la mayoría de los casos rige tal selección consciente de determinados segmentos de huesos de camélidos, con el fin de ornamentarlos con la compleja iconografía de El Sacrificador, ya sea con la variante felino como con la del venado andino ${ }^{15}$.

Respecto a la función de cajitas o contenedores propuesta por Le Paige para estos artefactos (en sus Notas les llamó "cajitas de hueso"), esto se verifica con las evidencias de los tubos Sin referencia 1 y con el de la tumba 132 de Solcor 3, así como por la descripción de Le Paige del contexto de la tumba 1371-72 de Quitor 4. En el primer caso (fig. 6; también figs. $2 \mathrm{~m}$ y $3 \mathrm{~m}$ ), el tubo no solo conservó la tapa de cuero y la cuerda de fibra de camélido que sirvieron para cerrar el extremo superior, con lo cual se evitó perder el contenido, sino también una tapa de calabaza para el extremo inferior. En el segundo caso, la tapita recortada de calabaza de encuentra hundida hacia el interior del tubo, y además, las notas de Le Paige son explícitas, en cuanto consignan que el tubo se encontraba tapado (tabla 1 y figs. 5,2 y $3 e$ ).

En consecuencia, basándonos en los paralelos iconográficos verificados entre tubos contenedores y tabletas para inhalar, así como en el estudio de los ajuares en los que los tubos aparecen junto a objetos de la parafernalia alucinógena, planteamos que dichos tubos formaron parte del círculo de dicho equipo, aun cuando esta idea no ha podido ser reforzada por medio del análisis químico orgánico. Aquí es importante señalar que la ausencia de evidencia molecular no impide que estos artefactos hayan contenido material vegetal asociado a las especies antes mencionadas, ya que dicha ausencia podría relacionarse con diversos factores, tales como: i) remoción de los contenidos residuales durante la excavación, ii) limpieza de los artefactos durante el ingreso a la colección, iii) degradación de los compuestos objetivos debido a procesos tafonómicos, y/o iv) aspectos analíticos como qué concentración de los compuestos estaban por debajo del límite de detección de la técnica utilizada, entre otros.

Proponemos también la existencia de una nueva variante (venado andino o taruca) para el ícono conocido como "El Sacrificador", ampliando así el círculo de las representaciones ya conocidas para el arte Tiawanaku en general. Al mismo tiempo, y como consecuencia de lo anterior, nuestro análisis reafirma el carácter foráneo de estas piezas importadas a Atacama y releva el carácter conspicuo de estos artefactos ofrendados en diversos contextos funerarios del área centro-sur andina. Resta para futuras investigaciones, indagar acerca de la naturaleza sagrada conferida al venado de los Andes, para lo cual el arte Moche y Huari aportan interesantes testimonios visuales, existiendo además tempranas evidencias de la importancia económica de este animal en los Andes meridionales (Mengoni Goñalons 1986, Díaz 1995). Asimismo, parece ineludible profundizar en el sacrificio humano por medio del desmembramiento. Ya mencionamos su aparición en la iconografía Pucara, a lo cual hay que agregar evidencias bioarqueológicas de la propia Akapana en Tiahuanaco (Manzanilla 1992, Kolata 1993), en donde se ha detectado el desmembramiento de cuerpos humanos (Janusek \& Bloom 2004) a través de huellas de corte que apuntan precisamente al patrón de miembros cercenados observados en los tubos que aquí hemos analizado.

Adendda. Mientras este trabajo era sometido a evaluación por esta revista científica, tuvimos conocimiento de la aparición del interesante artículo de Trigo, D. \& Hidalgo, R., 2018, titulado "El Decapitador venado en la iconografía Tiwanaku: orígenes, desarrollo y significados" (en Arqueología boliviana 4), Se trata por tanto de una notable coincidencia temática, puesto que dichos autores abordan igualmente la definición de El Sacrificador en su variante venado; para ello utilizaron algunas de las analogías presentadas aquí por nosotros, aunque el enfoque y las interpretaciones derivadas de su análisis difieren de las nuestras.

Agradecimientos a Verónica Cereceda de la Fundación Asur (Antropólogos del Sur Andino) y directora del Museo de Arte Indígena de Sucre, Bolivia, quien con su calidez habitual nos prestara todo tipo de facilidades para estudiar el tubo de Pulacayo. Agradecemos igualmente al colega Javier Méncias por los contactos previos para conseguir acceso al ejemplar del Museo de Metales Preciosos Precolombinos en La Paz, el cual se materializó gracias a la gestión de Vania Coronado, Jefa de la Unidad de Museos Municipales de la Secretaría Municipal de Culturas, y de Jaime Quispe, Encargado de dicho museo. Gratitud también a Paz Núñez-Regueiro por su amable asistencia durante nuestra estadía en el Musée du quai Branly, París. A Arturo Torres de la Vega, director del Museo Arqueológico R.P. Gustavo Le Paige S. J., de la Universidad Católica del Norte, así como a Jimena Cruz, 
Encargada de Colecciones de la misma institución. A Isabel Sidéra y Alexandra Legrand-Pineau, quienes presentaran una versión preliminar de este trabajo en la $12^{\circ}$ Reunión del Grupo de Investigación sobre Hueso Trabajado del International Council for Archaeozoology (ICAZ), evento realizado en mayo del 2017 en Granada, España. Queremos además mencionar y agradecer que esta investigación ha sido financiada por el proyecto FONDECYT 1160849, titulado "Estudio multidisciplinario del sistema religioso atacameño: parafernalia alucinógena, cronología y diferenciación social (500-1500 DC)".

\section{NOTAS}

${ }^{1}$ Todos los dibujos que acompañan este artículo fueron realizados por el dibujante patrimonial Alex Olave, a quien agradecemos su dedicación y esmero.

${ }^{2}$ Conviene destacar que el antropomorfo del tubo de la figura 6 difiere grandemente en cuanto a estilo del resto de tubos de la muestra. De hecho, lo acompañan pájaros inusualmente naturalistas, en una configuración general distinta a lo conocido para el área circum-Titicaca, por lo cual pensamos que pudiese provenir de tierras del oriente boliviano.

${ }^{3}$ Chávez señala precisamente este tipo de ojo y la presencia de adorno ocular como evidencia de la condición "sobrenatural" de personajes representados en la iconografía Pucara (Chávez 1992). Por su parte, Cook (1994) amplia a ocho los diferentes atributos de lo sobrenatural para Tiawanaku y Huari, entre ellos los ojos "bisecados vertical u horizontalmente" (Cook 1994: 178).

${ }^{4}$ Dicho elemento ha sido identificado por Torres en 15 tabletas para inhalar alucinógenos, en ocho de las cuales simboliza el término superior del cetro portado por los seres sobrenaturales en ellas representados (Torres 1985).

${ }^{5}$ En relación con este elemento, el tubo 8 exhibe la versión más compleja, pues en lugar de la tripartición característica presenta diversas figuras geométricas inscritas en el interior, tales como una voluta $\mathrm{S}$ dispuesta de manera horizontal en la parte inferior, una suerte de U sobre esta, y seis figuras semicirculares concéntricas en la parte superior (fig. 8).

${ }^{6}$ Respecto de los dibujos realizados tempranamente por Le Paige relevando la iconografía de estos cuatro tubos, debemos señalar que en ocasiones este autor no incluyó -quizás por la dificultad ocasionada por el deterioro de la pieza o por no haber comprendido la naturaleza de las imágenes- algunos detalles que resultan ser especialmente relevantes para definir actualmente a la variante taruca de El Sacrificador. Los casos más notorios son: en el tubo de la tumba 2139-40 de Quitor 5 no advirtió la cabeza humana y tampoco la pierna cortada con pie que surgía del tocado del personaje (fig. 7; Le Paige 1965: lám. 50). En el tubo "A" de la tumba 1973-76 de Quitor 5, omitió el dibujo de la pierna cortada incorporada al tocado, así como también la cabeza cortada del remate del cetro (fig. 8; Le Paige 1965: lám. 54); a su vez, del dibujo del tubo de la tumba 5392 de Quitor 6, no reconoció el cetro como una figura humana de cuerpo completo con características de cautivo (fig. 10; Le Paige 1965: lám. 55).

${ }^{7}$ Un fechado Ams realizado sobre un fragmento de este tubo de hueso arrojó un resultado de $1250+/-40$ años AP, lo cual significa un rango calibrado de 674- 874 DC (Cruz 2009: 5).

${ }^{8}$ En relación con las excavaciones realizadas por Bennett en Pariti, este da cuenta del hallazgo de cinco tubos grabados con iconografía Tiawanaku clásica (Bennett 1936: fig. 30m, n, p, q, r). Por el contrario, Posnansky reproduce el dibujo de dos tubos contenedores pintados con diseños igualmente clásicos, aunque llamándolos equivocadamente "tubos de absorción" (Posnansky 1945: Plato XCIII a-f).

9 En los ejemplares altiplánicos -incluyendo el tubo grabado 12- se aprecia el mismo recurso ya observado de enmarcar el borde superior con distintos tipos de franjas, y delimitar así el espacio con diseño.

${ }^{10}$ Chávez, analizando la iconografía Pucara establece lo siguiente en la relación "hombre felino" y la presencia de partes del cuerpo humano desmembradas: "The legs can be cut at the thight o femoral region or at the hip, and are bent with a semi-circle at the knee. There are striking similarities between the feline man and the severed legs, arms, and some of the severed heads- a situation which made indicate that those body parts correspond to same feline men victims" (Chávez 2002: 54).

${ }^{11}$ La opción de cuerpo humano completo se observa igualmente en el tocado y en el remate del cetro de El Sacrificador-humano de la túnica de Pulacayo (Agüero 2007: 90), marcando con ello un interesante paralelo iconográfico entre lo plasmado tanto en textiles como en tubos de hueso (fig. 10).

${ }^{12}$ Estas cabezas resultan ser similares a los casos de la figura 5 (colgando del codo y sobre su espalda) y figura 7 (surgiendo como un elemento aparte de la figura de El Sacrificador mismo).

${ }^{13}$ Se trata de 15 tabletas, todas de estilo tiawanaku. Conviene señalar que en parte hemos tomado como referencia para el análisis estilístico los 26 elementos señalados por Torres 1984b como rasgos propios de dicho arte): tableta 9075 de Catarpe 5, tumba 2351; tableta 9117 de Coyo Oriente, tumba 4008; tableta 9116 de Coyo Oriente, tumba 4141; tableta 9163 de Quitor 5, tumba 2189-2192; tableta 9164 de Quitor 5, tumba 2196-2198; tableta 20.945 de Quitor 5, tumba 3380; tableta 9084 de Quitor 6, tumba 3613; tableta 9110 de Quitor 6, tumba 5444; tableta 9274 de Quitor 6, tumba 2477-2481; tableta 9106 de Quitor 8, tumba 3229-3230; tableta 9047 de Sequitor Alambrado Oriental, tumba 1660; tableta 2491 de Solcor 3, tumba 69; tableta 8432 de Solcor 3, tumba 107; tableta 13.166 de Solcor 3, tumba 117; tableta 8844 de Toconao Oriente, tumba 4229-4230.

${ }^{14}$ Dentro de este tema específico, véanse los análisis iconográficos de Torres 2001, Llagostera 2006, así como también Trigo e Hidalgo 2009. 
${ }^{15}$ Aquí debemos mencionar el ejemplar con Sacrificador-taruca grabado del cementerio Azapa 75 en Arica, en cuyo tocado se observa cuernos de venado y una pierna cortada (Muñoz 1995-1996: lám. 8); en técnica de pintura, el Sacrificador-felino excavado en la Akapana de Tiahuanaco por Janusek (2004: fig. 7.5A); el tubo 3607 grabado con Sacrificador-felino exhibido en el INIAM-UMSS, Cochabamba, Bolivia; el ejemplar grabado del Museo de Denver, Estados Unidos, que entre los elementos de su tocado no solo figuran astas de venado, sino también una pierna cortada, a juzgar por la fotografía publicada (Young Sánchez 2004: fig. 4.18).

\section{REFERENCIAS}

AgüEro, C. 2003. Componente Tiwanaku vs. componente local en los oasis de San Pedro de Atacama. In Tejiendo sueños en el cono sur. Textiles andinos: pasado, presente y futuro, V. Solanilla, Ed., pp. 180-198. Barcelona: Grup d'Estudis Precolombins-Universitat Autònoma de Barcelona.

AgüERo, C. 2007. Los textiles de Pulacayo y las relaciones entre Tiwanaku y San Pedro de Atacama. Boletín del Museo Chileno de Arte Precolombino 12 (1): 85-98.

Agüero, C., Uribe, M. \& Berenguer, J. 2003. La iconografía Tiwanaku: el caso de la escultura lítica. Textos Antropológicos 14 (2): 47-82.

Agüero, C. \& Uribe, M. 2014. Rethinking the Tiwanaku phenomenon in San Pedro de Atacama through the study of textiles of Solcor 3 and their associated contexts (400-1000 AD). Textile Society of America Symposium Proceedings Textile Society of America Paper 934, pp. 1-12.<http://digitalcommons.unl.edu/tsaconf/934> [consultado: 11-06-2019].

Aschero, C. 1979. Un asentamiento acerámico en la quebrada de Inca Cueva (Jujuy). Informe preliminar sobre el sitio Inca Cueva C-4. In Actas Jornadas de Arqueología del noroeste argentino, pp. 159-183. Jujuy: Universidad de El Salvador.

Bennett, W. 1936. Excavations in Bolivia. Anthropological papers of the American Museum of Natural History XXXV (IV): 329-507.

Berenguer, J. 1987. Consumo nasal de alucinógenos en Tiwanaku: una aproximación iconográfica. Boletín del Museo Chileno de Arte Precolombino 2: 33-53.

Berenguer, J. 1998. La iconografía del poder en Tiwanaku y su rol en la integración de zonas de frontera. Boletín del Museo Chileno de Arte Precolombino 7: 19-37.

Berenguer, J. 2000. Tiwanaku: señores del lago sagrado. Santiago: Museo Chileno de Arte Precolombino.

Carrasco, C., Echeverría, J., Ballester, B. \& Niemeyer, H. 2015. De pipas y sustancias: costumbres fumatorias durante el Período Formativo en el litoral del desierto de Atacama (norte de Chile). Latin American Antiquity 26: 143-161.

Cartajena, I., Núñez, L. \& Grosjean, M. 2007. Camelid domestication on the western slope of the Puna de Atacama, northern Chile. Anthropozoologica 42: 155-173.
CHÁvez, S. 1992. The conventionalized rules in Pucara pottery technology and iconography: implications for socio-political development in the northern lake Titicaca basin. Tesis para optar al grado de Doctor, Department of Anthropology, Michigan State University.

Chávez, S. 2002. The identification of the camelid woman and the feline man: themes, motifs, and designs in Pucara style pottery. In Andean archaeology II: Art, landscape and society, H. Silverman \& W. Isbell, Eds., pp. 35-69. New York: Kluwer Academic-Plenum Publishers.

Cook, A. 1984. The Middle Horizon ceramic offerings from Conchopata. Ñawpa Pacha: 49-90.

Cook, A. 1994. Wari y Tiwanaku: entre el estilo y la imagen. Lima: Pontificia Universidad Católica del Perú.

Couture, N. \& SAMPECK, K. 2003. Putuni. A history of palace architecture at Tiwanaku. In Tiwanaku and its hinterland: archaeology and paleoecology of an Andean civilitation: 2 Urban and rural archaeology, Alan L. Kolata, Ed., pp. 226-263. Washington: Smithsonian Institution Press.

Cruz, P. 2009. Tumbas, metalurgia y complejidad social en un páramo del altiplano surandino. Pulacayo, Bolivia, primer milenio DC. Revista Andina 49: 71-104.

DíAz, N. I. 1995. Antecedentes sobre la historia natural de la taruca (Hippocamelus antisensis d' Orbigny 1834) y su rol en la economía andina. Chungara 27 (1): 45-55.

Echeverría, J., Planella, M. T. \& Niemeyer, H. M. 2014. Nicotine in residues of smoking pipes and other artifacts of the smoking complex from an Early Ceramic Period archaeological site in central Chile. Journal of Archaeological Science 44: 55-60.

Echeverría, J. \& Niemeyer, H. M. 2013. Nicotine in the hair of mummies from San Pedro de Atacama (Northern Chile). Journal of Archaeological Science 40: 3561-3568.

Gili, F., Albornoz, X., Echeverría, J., García, M., Carrasco, C., Meneses, F. \& Niemeyer, H. M. 2016. Vilca, encuentro de miradas: antecedentes y herramientas para su pesquisa en contextos arqueológicos del área centro sur andina. Chungara 48: 589-606.

Gili, F., Echeverría, J., Stovel, E., Deibel, M. \& Niemeyer, H. M. 2017. Las pipas del salar de Atacama: reevaluando su origen y uso. Estudios Atacameños 54: 37-64.

Horta T., H. 2012. El estilo Circumpuneño en el arte de la parafernalia alucinógena prehispánica (Atacama y Noroeste Argentino). Estudios Atacameños 43: 5-34.

Horta T., H. 2014. Lo propio y lo ajeno. Definición del estilo San Pedro en la parafernalia alucinógena de los oasis del salar de Atacama. Chungara 46 (4): 559-583.

Ibarra Grasso, D. \& Querejazu Lewis, R. (Eds.) 1986. 30.000 años de prehistoria en Bolivia. La Paz: Los amigos del libro.

IsBell, H. \& KNOBLOCH, P. 2008. Missing links, imaginary links: staff god imagery in the South Andean past. In Andean archaeology III, North and south, W. Isbell \& H. Silverman, Eds., pp. 307-351. New York: Springer. 
JANUSEK, J. W. 2003. Vessels, time, and society: toward a ceramic chronology in the Tiwanaku heartland. In Tiwanaku and its hinterland: archaeology and paleoecology of an Andean civilization, Volume 2, A. L. Kolata, Ed., pp. 30-89. Washington: Smithsonian Institution Press.

JANUSEK, J. W. 2004a. Identity and power in the ancient Andes. Tiwanaku cities through time. New York-London: Routledge.

JANUSEK, J. W. 2004b. Tiwanaku and its precursors: recent research and emerging perspectives. Journal of Archaeological Research 12: 121-183.

JANUSEK, J. W. 2006. The changing 'nature' of Tiwanaku religion and the rise of an Andean state. World Archaeology 38 (3): 469-492.

JANuseK, J. W. 2008. Ancient Tiwanaku. Cambridge: Cambridge University Press.

JANUSEK, J. W. \& BLOM, D. E. 2004. Making place: humans as dedications in Tiwanaku. World Archaeology 36 (1): 123-141.

Knobloch, P. 2000. Wari ritual power at Conchopata: an interpretation of Anadenanthera colubrine iconography. Latin American Antiquity 11: 387-402.

Kolata, A. 1993. The Tiwanaku. Portrait of an Andean civilization. Cambridge: Blackwell Publishers.

Lechtman, H., Cruz, P., Macfarlane, A. \& Carter, S. 2010. Procesamiento de metales durante el Horizonte Medio en el altiplano surandino (Escaramayu, Pulacayo, Potosí, Bolivia). Boletín del Museo Chileno de Arte Precolombino 15 (2): 9-27.

Lema, V. 2017. Del objeto al contexto: la(s) capa(s) "E" de Huachichocana III. Chungara 49 (2): 209-226.

Le PAige, G. 1964. El Precerámico en la cordillera atacameña y los cementerios del Período Agroalfarero de San Pedro de Atacama. Anales de la Universidad del Norte 3.

Le Paige, G. 1965. San Pedro de Atacama y su zona (14 temas). Anales de la Universidad del Norte 4.

Llagostera, A. 1995. Art in the snuff trays of the San Pedro de Atacama (Northern Chile). In Andean art: visual expression and its relations to Andean beliefs and values, $\mathrm{P}$. Dransart, Ed., pp. 51-77. London: Worldwide Archaeology Series, Vol. 13.

Llagostera, A. 2006. Contextualización e iconografía de las tabletas psicotrópicas Tiwanaku de San Pedro de Atacama. Chungara 38 (1): 83-111.

ManZanilla, L. 1992. Akapana: una pirámide en el centro del mundo. Mexico City: Ediciones UnAm.

Manzanilla, L. \& Woodard, E. 1990. Restos humanos asociados a la pirámide de Akapana (Tiwanaku, Bolivia). Latin American Antiquity 1 (2): 133-149.

Makowski, K. 2001a. El panteón de Tiahuanaco y las deidades con báculos. In Los dioses del antiguo Perú, K. Makowski, Ed., pp. 67-107. Lima: Banco de Crédito.

Maкоwsкi, K. 2001b. Los personajes frontales de báculos en la iconografía Tiahuanaco y Huari: ¿Tema o convención? Boletín de Arqueología PUCP 5: 337-374.
Makowski, K. 2009. Royal statues, staff gods, and the religious ideology of the prehistoric state of Tiwanaku. In Tiwanaku: papers from the 2005 Mayer Center Symposium at the Denver Art Museum. M. Young-Sánchez, Ed., pp. 133-164. Denver: Denver Art Museum.

Mengoni Goñalons, G. L. 1986. Vizcacha (Lagidium viscacia) and Taruca (Hippocamelus sp.) in early south Andean economies. In Archaeozoologia, Mélanges, P. Ducos, Ed., pp. 63-71. Bordeaux: La pensée sauvage.

Minkes, W. 2005. Warp the dead. The funerary textile tradition from the Osmore valley, south Peru, and its social-political Implications. Tesis para optar al grado de Doctor en Arqueología, Archaeological Studies Leiden University, Leiden.

Möntell, G. 1929. Dress and ornaments in ancient Peru. Archaeological and Historical Studies. Gothenburg: Elanders Boktryckeri Aktiebol AG.

MuÑoz, I. 1995-1996. Poblamiento humano y relaciones interculturales en el valle de Azapa: nuevos hallazgos en torno al Período Formativo y Tiwanaku. Diálogo Andino 14/15: 241-277.

Niemeyer, H. M., De Souza, P., Camilo, C. \& Echeverría, J. 2018. Chemical evidence of prehistoric passive tobacco consumption by a human perinate (Early Formative Period, South-Central Andes). Journal of Archaeological Science 100: 130-138.

Niemeyer, H., Salazar, D., Horta, H. \& Gómez-Peña, F. 2015. New insights into the Tiwanaku style off snuff trays from San Pedro de Atacama, northern Chile. Latin American Antiquity 26 (1): 120-136.

NúÑEZ, L. 1964. El sacrificador. Un elemento co-tradicional andino. Noticiero Mensual Museo Nacional de Historia Natural 96.

OAKLAND, A. 1992. Textiles and ethnicity: Tiwanaku in San Pedro de Atacama, North Chile. Latin American Antiquity 3: 316-340.

Pacheco, V., Altamirano, A. \& Guerra, E. 1986. The osteology of south american camelids. Los Angeles: Institute of Archaeology-University of California.

PAredes, R. 1984. El “degollador" (Nakaq) de Altarane, Puno. Gaceta Arqueológica Andina 11.

Posnansky, A. 1945. Tihuanacu: la cuna del hombre americano. Volume I y II. New York: J. J. Augustin.

Posnansky, A. 1957. Tihuanacu: la cuna del hombre americano, vols. III-IV. La Paz: Ministerio de Educación.

Reinhard, J. 1991. Tiwanaku: ensayo sobre su cosmovisión. Pumapunku 7: 9-66.

Richardin, P., Lavier, C., Horta, H., Figueroa, V. \& Lira, N. 2015. Radiocarbon dating of Atacama (Chile) snuff trays: an update on stylistic and chronological correlations. Radiocarbon, an International Journal of Cosmogenic Isotope Research 57 (5): 775-784.

SAgÁrnaga, J. \& KorpisaAri, A. 2007. Hallazgos en la isla de Pariti echan nuevas luces sobre los "chachapumas" tiwanakotas. Chachapuma 2: 6-28. 
Saladié, P., Huguet, R., Díez, C., Rodríguez-Hidalgo, A., Cáceres, I., Vallverdú, J., Rosell, J., Bermúdez de Castro, J. M. \& CARbonell, E. 2011. Carcass transport decisions in Homo antecessor subsistence strategies. Journal of Human Evolution 61: 425-446.

Santander, B. Ms. 2016. Análisis de tubos óseos. Proyecto FONDECYT 1160849: Estudio multidisciplinario del sistema religioso atacameño: parafernalia alucinógena, cronología y diferenciación social (500-1500 DC).

SAwyer, A. 1963. Tiahuanaco tapestry design. Textile Museum Journal (1) 2: 27-38.

Sierpe, V. 2015. Atlas osteológico del guanaco (Lama guanicoe). Punta Arenas: Ediciones Universidad de Magallanes.

Stovel, E. 2005. The Archaeology of identity construction: ceramic evidence from Northern Chile. In Global archaeological theory. Contextual voices and contemporary thoughts. P. Funari, P., Zarankin \& E. Stovel, Eds., pp. 145-166. New York: Kluwer Academic-Plenum Publishers.

Stovel, E. 2008. Interaction and social fields in San Pedro de Atacama, Northern Chile. In The Handbook of South American Archaeology, H. Silverman \& W. H. Isbell, Eds., pp. 979-1002. Berlin: Springer.

TARragó, M. 1989. Contribución al conocimiento arqueológico de las poblaciones de los oasis de San Pedro de Atacama en relación con los otros pueblos puneños, en especial, el sector septentrional del valle Calchaquí. Tesis para optar al título de Doctor en Historia, Especialidad Antropología. Universidad Nacional de Rosario, Facultad de Humanidades y Artes, Argentina.

Torres, C. M. 1984a. Tabletas para alucinógenos de San Pedro de Atacama: estilo e iconografía. In Tesoros de San Pedro de Atacama. Santiago: Museo Chileno de Arte Precolombino.

Torres, C. M. 1984b. Iconografía de las tabletas para inhalar substancias psicoactivas de la zona de San Pedro de Atacama, norte de Chile. Estudios Atacameños 7: 178-195.

Torres, C. M. 1985. Estilo e iconografía Tiwanaku en las tabletas para inhalar substancias psicoactivas. Diálogo Andino 4: 223-245.

Torres, C. M. 1987. The iconography of South American snuff trays and related paraphernalia. Etnologiska Studier 37.

Torres, C. M. 2001. Iconografía Tiwanaku en la parafernalia inhalatoria. Huari y Tiwanaku: modelos versus evidencias. Boletín de Arqueología PUCP 5: 247-454.

Torres, C. M. \& Conklin, W. 1995. Exploring the San Pedro de Atacama/Tihuanaku Relationship. In Andean Art: Visual Expression and his Relation to Andean Beliefs and Values. P. Dransart, Ed., Vol. 13, pp. 78-108. Avebury: Worldwide Archaeology Series.

Torres, C. M. \& Repke, D. B. 2006. Anadenanthera. Visionary Plant of Ancient South America. New York: The Haworth Herbal Press.

Torres-Rouff, C., Knudson, K. J., Pestle, W. \& Stovel, E. M. 2015. Tiwanaku influence and social inequality: a bioarchaeological, biogeochemical, and contextual analysis of the Larache cemetery, San Pedro de Atacama, Northern Chile. American Journal of Physical Anthropology 158 (4): 592-606.

Trigo, D. 2013. Las implicancias simbólicas del personaje "Arquero" en la iconografía de Tiwanaku durante el Horizonte Medio (500 DC-1150 DC) Tesis de licenciatura en Arqueología, Universidad Mayor de San Andrés (UMSA), La Paz.

Trigo, D. \& Hidalgo, R. 2009. La relación iconográfica de los pies, piernas y cabezas en Tiwanaku y Huari: el caso de los decapitadores y sus coronas durante el Horizonte Medio. Actas de la XXıI Reunión Anual de Etnología, Tomo 1, pp. 3-13. La Paz: Museo Nacional de Etnografía y Folklore.

Uribe, M. \& AGÜERo, C. 2001. Alfarería, textiles y la integración del Norte Grande de Chile a Tiwanaku. Boletín de Arqueología PUCP 5: 397-426.

VALCÁRCEL, L. 1959. Símbolos mágico-religiosos en la cultura andina. Revista del Museo Nacional de Lima 28: 3-18.

Villanueva, J. 2007. Las escudillas del rasgo 1 en la Isla de Pariti: Interpretación y consideraciones desde un enfoque iconográfico. Chachapuma: Revista de Arqueología Boliviana 1: 53-63.

VillanueVA, J. \& KoRPISAARI, A. 2013. La cerámica tiwanaku de la isla Pariti como recipiente: performances y narrativas. Estudios Atacameños 46: 83-108.

Young-Sánchez, M. (Ed.) 2004. Tiwanaku: ancestors of the Inca. Denver-Lincoln: Denver Art Museum-University of Nebraska Press. 